\title{
Multisource spatial data integration for use cases applications
}

\section{Francesca Noardo ${ }^{1}$}

3D geoinformation group, Urbanism Department, Delft University of Technology, Delft, The Netherlands

${ }^{1}$ Corresponding author - f.noardo@ tudelft.nl, ORCID:0000-0003-2269-5336

Francesca Noardo graduated in Architecture and had her $\mathrm{PhD}$, developed in the geomatics field, at the Politecnico di Torino (Italy). From 2018 she is postdoc researcher in the 3D geoinformation group at the Delft University of Technology. She works towards the integration of multi-source spatial data, in particular, detailed 3D information systems (from survey or from design), in interoperable 3D maps, having semantics from open standards and correct geometry. The aim is the concrete employment of such technology for urban applications, within her EUMSC research and other use case-related projects, in particular related to the digitalization of building permit issuing and city applications. She coordinates an international multidisciplinary collaboration as founder and leader of the European Network for Digital Building Permits (EUnet4DBP).

\section{Acknowledgements}

This study has received funding from the European Union's Horizon 2020 research and innovation programme under the Marie Skłodowska-Curie Leading Fellow Postdoc programme, grant agreement no. 707404, project "Multisource spatial data integration for smart city applications". I'd like to thank the 3D geoinformation group at TU Delft, who gave great support and inspiration to my research. 


\title{
Multisource spatial data integration for use cases applications
}

\author{
Big opportunities are given by the reuse and integration of data, which, \\ nowadays, are more and more available, thanks to advances in acquisition and \\ modelling technologies and the open data paradigm. Seamlessly integrating data \\ from heterogenous data sources has been an interest of the geospatial community \\ for long time. However, the higher semantic and geometrical complexity pose \\ new challenges which have never been tackled in a comprehensive methodology. \\ Building on the previous theories and studies, this paper proposes an overarching \\ methodology for multisource spatial data integration. Starting from the definition \\ of the use case-based requirements for the integrated data, it proposes a \\ framework to analyse the involved datasets with respect to integrability and \\ suggests actions to harmonise them towards the destination model. The overall \\ workflow is explained, including the data merging phase and validation. The \\ methodology is tested and exemplified on a case study. Considering the specific \\ data sets' features and parameters, this approach will allow the development of \\ consistent, well documented and inclusive data integration workflows, for the \\ sake of use cases processes automation and the production of Interoperable and \\ Reusable data.
}

Keywords: data integration; interoperability; harmonization; GeoBIM; metadata.

\section{Introduction}

The integration of spatial information from heterogeneous sources has been of interest in the geomatics community for a long time. For the professional use of spatial data, the effective interaction of multi-source data would be extremely useful. Recently, the new opportunities given by the technological developments in acquisition and surveying techniques, which allow the generation of high amounts of data, as well as the technologies to share the data, mainly through the web (e.g., open data, linked data), opened new perspectives towards the reuse of existing data for further use cases than the ones for which they were originally collected.

However, although many initiatives have been developed towards interoperability, such as standardization actions, ontology-related research (Kavouras, Kokla, 2007), GeoBIM research (for the integration of geoinformation and Building Information Models), a comprehensive methodology for multi-source data integration has not been proposed yet.

Mohammadi et al. (2006) identify the aspects to be considered for the data integration as: institutional, policy, legal and social, besides technical. This paper is focused on the technical side of the integration.

According to Kavouras and Kokla (2007), to build an integrated view of heterogeneous systems requires: identifying the heterogeneities; analysing importance 
and priorities; solving them through a systematic strategy. Wiemann and Bernard (2016) define the steps for data integration, called 'data fusion' as: data search and retrieval; data enhancement; harmonization; relation measurement; feature mapping; resolving; data provision. They propose an interesting approach based on linked data. Mohammadi et al. (2010) proposed a methodology and a tool to facilitate spatial data integration within spatial data infrastructures, considering the technical and nontechnical issues. However, the increased complexity of data available nowadays (3D, deep and complex data structures) presents new challenges from the technical point of view that need to be tackled to achieve an effective integration.

Existing efforts, often consider mainly the semantic and structural aspects for data integration (e.g. Lenzerini, 2002). For example, Kavouras and Kokla (2007) outline relevant methodologies for ontologies integration, which are partially re-used, adapted and eventually referred within this paper. However, their focus is on semantics and structure, while it is important for this study to consider the complexity of geometry as a separate issue. Furthermore, data from practice hardly reach the complexity considered by Kavouras and Kokla (2007).

Other cases report methods to merge the geometric information from multiple sources or sensors ('data fusion') (e.g. Dong et al., 2018; Ramos, Remondino, 2015; Zhu, Donia, 2013; Ahn et al., 2020). More complete database integration was also studied, but still for 2D GIS (Devogele et al., 1998, Uitermark et al., 2005).

Standardization efforts have been intended to solve the interoperability, and consequently integration, issues. However, their development is still little aligned with their implementation in software and adoption in practice (Noardo et al., 2020, 2021a,b,c), which makes the original aim of standardization still an open problem (Section 1.1).

In this paper, the detailed features of spatial data are analysed, including for the recent complex 3D information systems, such as Building Information Models (BIM) and $3 \mathrm{D}$ city models. The need of processing towards harmonization of the data is defined accordingly, and some relevant available methods to perform such processing are mentioned as initial guidance. Those phases are inserted in an overall workflow guiding from the choice of the input datasets until the final merging and validation of the harmonised data. A critical starting step to initiate a successful integration process is here identified in the definition of the requirements for the finally obtained integrated data, in a way that can be effective to support a variety of use cases applications. A concrete and well-defined scope and use of the data (including software and procedural details) is the preferable way to success and allows validation and testing.

The adopted approach strongly relates on the definition of requirements for the integrated data, and decomposes the integration into sub-issues, to be analysed and tackled in detail. It is an innovative aspect of this work, which proposes a pragmatic workflow to support data integration in practice.

The methodology, integrating methods common in ontology engineering and data fusion, is described in Section 2. The results are explained starting from the proposed integration workflow (Section 3) and the parameters and specific features to be considered in the integration (Section 3.1). After some suggestions for data requirements definition (Section 3.2) and data retrieval (Section 3.3), a rubric to analyse each feature or parameter of the input data, assessing their potential for integration, is proposed in Sections 3.4 and 3.5. In Section 3.6, a range of methods are mentioned to tackle the processing pointed out by such analysis and assessment. Finally, Section 3.7 presents methods for fusing the harmonised data, and validation. The proposed methodology is exemplified in a case study (Section 4). The discussion (Section 5) 
follows, including the potential automation of the proposed workflow (Section 5.1) and an analysis of metadata standards (Section 5.2) to possibly support the preliminary analysis.

\subsection{Open standards and related issues}

To support interoperability and integration, Open standards are published for different domains. For the representation of city and wider portions of land, CityGML ${ }^{1}$ was published by the Open Geospatial Consortium (OGC). OGC also recognised CityJSON ${ }^{2}$ (Ledoux et al., 2019) as community standard, intended to improve usability of CityGML, mainly by means of a different implementation. INSPIRE ${ }^{3}$ and its proposed data model is a further reference for the representation of city and landscape, prescribed by the European Directive 2007/2/EC aimed at providing a common data infrastructure to support environmental policies across Europe. To represent infrastructure knowledge from a geospatial point of view, the OGC LandInfra ${ }^{4}$ was published. In the field of Architecture Engineering Construction and Operations, mainly for buildings, other standards have been developed, such as the Industry Foundation Classes ${ }^{5}$, by buildingSMART, or gbXML ${ }^{6}$ with the specific scope of representing energy-related features of buildings, to support analysis.

However, these standards also present disadvantages, like the big efforts for producing compliant data or the reduced flexibility in some cases (Doerr, 2004). At the same time, they often propose very comprehensive schemas, aiming at covering the entire domain, and leave the possibility open to use the model in very different ways, to adapt to different use cases' needs. However, interoperability and integration processes suffer from this, because data become quite unpredictable, even if compliant to the same standard. It is essential to know how the (often ambiguous) models were interpreted, with respect to structure, semantics and geometry, and how the structure was used, e.g., which of the allowed options is used to store some specific information, such as georeferencing (Clemen, Görne, 2019). In addition, extensions and generic entities can be used to extend the prescribed model further, resulting in an even wider possibility to produce standard-complaint conflicting data. Clear definitions and examples are seldom available to allow a consistent use of the standard data models (including interpretation of classes meaning, attributes and relationships).

Moreover, when considering the use and implementation into concrete tools and data from practice, they often present issues (Noardo et al., 2020, 2021a,b,c) and are not used consistently enough to provide fully automatically interoperable and integrable data.

\footnotetext{
${ }^{1}$ https://www.ogc.org/standards/citygml [Accessed 1st December 2021]

2 https://www.cityjson.org [Accessed 1st December 2021]

${ }^{3}$ https://inspire.ec.europa.eu [Accessed $1^{\text {st }}$ December 2021]

${ }^{4}$ https://www.ogc.org/standards/landinfra [Accessed 1st December 2021]

${ }^{5}$ https://www.buildingsmart.org/standards/bsi-standards/industry-foundation-classes/ [Accessed

$1^{\text {st }}$ December 2021]

${ }^{6}$ https://www.gbxml.org [Accessed $1^{\text {st }}$ December 2021]
} 
Figure 1 shows an example of three 3D city models of Rotterdam (NL). One is the 3D city model developed by the City of Rotterdam ${ }^{7}$, the second was generated by the software 3dfier (Ledoux et al., 2021) and the third one is the Basisregistratie Grootschalige Topografie (BGT), the Dutch national topographic map, and is structured according to the $\mathrm{IMGeo}^{8}$ data model, which is modelled as an Application Domain Extension (ADE) of CityGML v.2 (Van den Brink et al., 2013a). All of them are CityGML-compliant. However, they result in quite different models (Colucci et al., 2020).

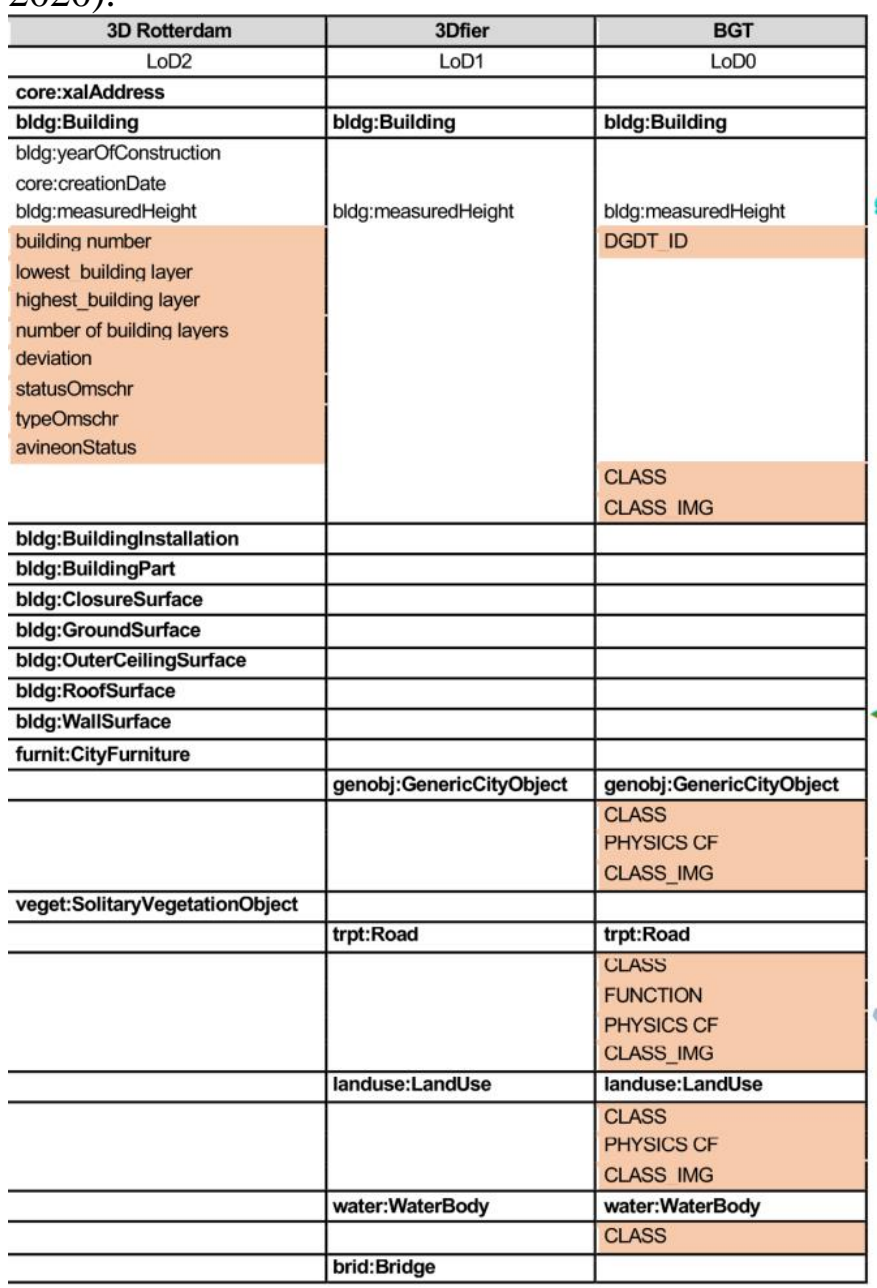
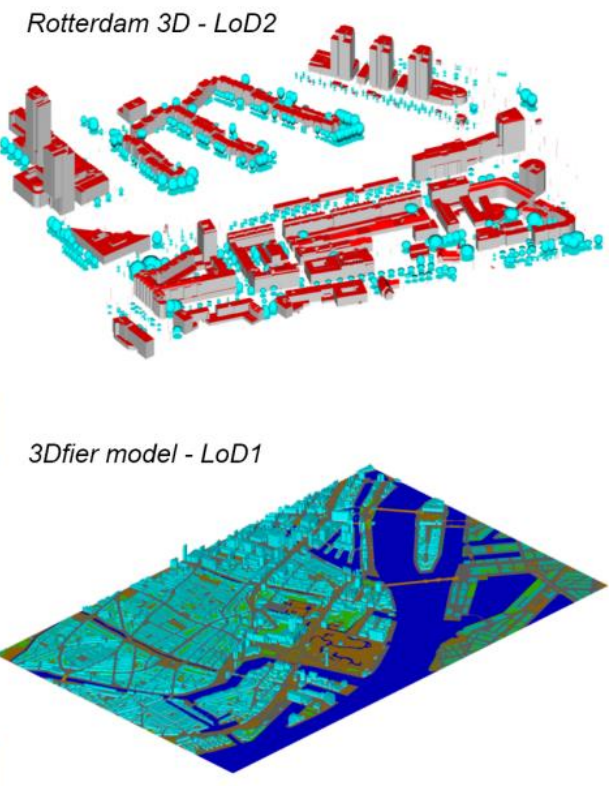

Figure 1. A comparison of entities, attributes (in pink the attributes used as generics) and visualization of three different CityGML-compliant models.

As a consequence, an in-depth analysis is necessary to consider the relevant parameters and characteristics involved in interoperability, explained in Section 3.1, even if the data are declared standard-compliant.

\subsection{Interoperability vs data integration}

The two concepts of interoperability and integration are often confused. However, even

\footnotetext{
${ }^{7}$ https://www.3drotterdam.nl/\#/ [Accessed $24^{\text {th }}$ November 2021]

${ }^{8}$ https://www.geonovum.nl/geo-standaarden/bgt-imgeo [Accessed 24th November 2021]
} 
if being strictly related, they have a different meaning.

Kavouras and Kokla (2007) state that 'interoperability is the ability of systems or products to operate effectively and efficiently in conjunction, on the exchange and reuse of available resources, services, procedures, and information, in order to fulfil the requirements of a specific task'. They add that 'it is not exhausted with integration, but also involves means of intelligent communication such as querying, extraction, transformation etc.'. In Noardo et al. (2021a,b) interoperability is defined as the ability of software to keep files consistent with themselves after import-export phases. Interoperability is a characteristic of single data, allowing their re-usability across systems.

Integration is instead the combination or conflation of information from different data sets (Worboys, Duckham, 2004).

Figure 2 depicts what the two concepts entail and how are they related to each other.

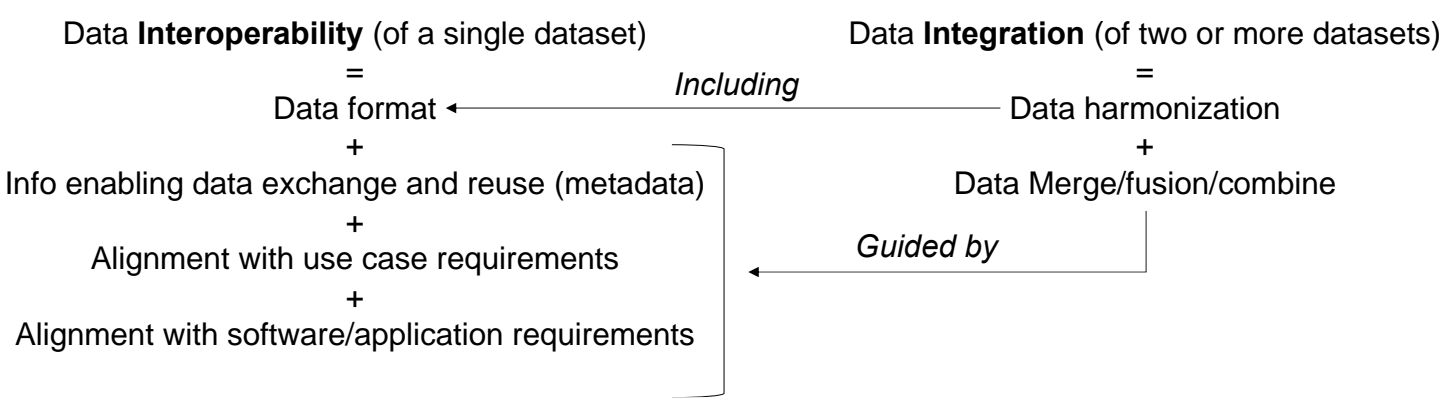

Figure 2. Data interoperability vs data integration.

\section{Materials and methods}

Reaping the results from recent studies on the integration of geoinformation and BIM (GeoBIM) and past data integration theories and experiences (Noardo, 2020a,b; Ellul, 2020; Biljecki, Tauscher, 2019; Arroyo Ohori et al., 2018; Noardo et al., 2016, Kumar et al., 2019; Ulubay, Altan, 2002; Laurini, 1998; Laurini, Thompson, 1992; Worboys Duckham, 2004; Kavouras, Kokla, 2007), the complex issue of spatial data integration is analysed in its components and a reference workflow is proposed.

Moreover, the relevant set of data parameters and aspects to be considered for the integration is explicated and organised into a framework in order to provide a reference for assessing the integration potential of datasets with respect to destination data requirements, on the one hand, as well as to guide in the harmonization.

Processing methods to transform and convert the input datasets, as necessary to harmonize them with the data requirements, are then suggested per each case, and potential usable methods are reviewed.

The methods to solve each of the steps in the integration workflow are many and need to be chosen according to the kind of processing needed and the kind of data involved. Therefore, in this paper it is not possible to give one recipe to fit all cases, but several methods from literature are proposed in order to overcome the most usual issues. The proposed framework is intended to point out the needs and guide in the process.

The proposed framework is finally validated and tested in a case study, regarding the update of a 3D city model by means of the integration of a BIM model of a newly designed building. The focus of the experiment is not on the processing itself, 
therefore, many steps were performed manually or by means of existing tools. Other similar cases were proposed, e.g., by Noardo et al. (2016) and van Heerden (2021).

\section{Results}

A workflow for an effective methodology for data integration is depicted in Figure 3. The integration effort for a specific use case is considered. Therefore, the essential starting point, critical in this methodology, is the definition of the requirements for the data to be obtained after the integration (Section 3.2). The parameters to be defined in the data requirements definition, as well as in the following phases, are listed in Section 3.1. In addition, the non-technical features, as defined in Mohammadi et al. (2006), must be planned. Based on such defined requirements, the input datasets must be retrieved in order to cover the defined need for information (Section 3.3). It is necessary to double check that the legal properties of input data are not conflicting with the integrated ones (e.g., copyright, privacy, licences and so on.). In case they conflict, either an adjustment should be done in integrated data requirements (i.e., future data specs), whether possible, or other data must be retrieved. Then, the assessment of data integrability must be performed, according to the framework proposed in Sections 3.4 and 3.5. From that analysis it can be assessed whether is possible to use the selected input data in the integration, and if the required effort is worth doing it. Otherwise, different data should be selected. If the assessment is positive, the harmonization actions (enrichment, generalization, conversion) must be chosen and applied for each aspect considered (Section 3.6). Data fusion will then allow obtaining the integrated data set (Section 3.7). Final steps are the validation of such data set against the defined data requirements and the update of metadata to keep track of the applied processing.

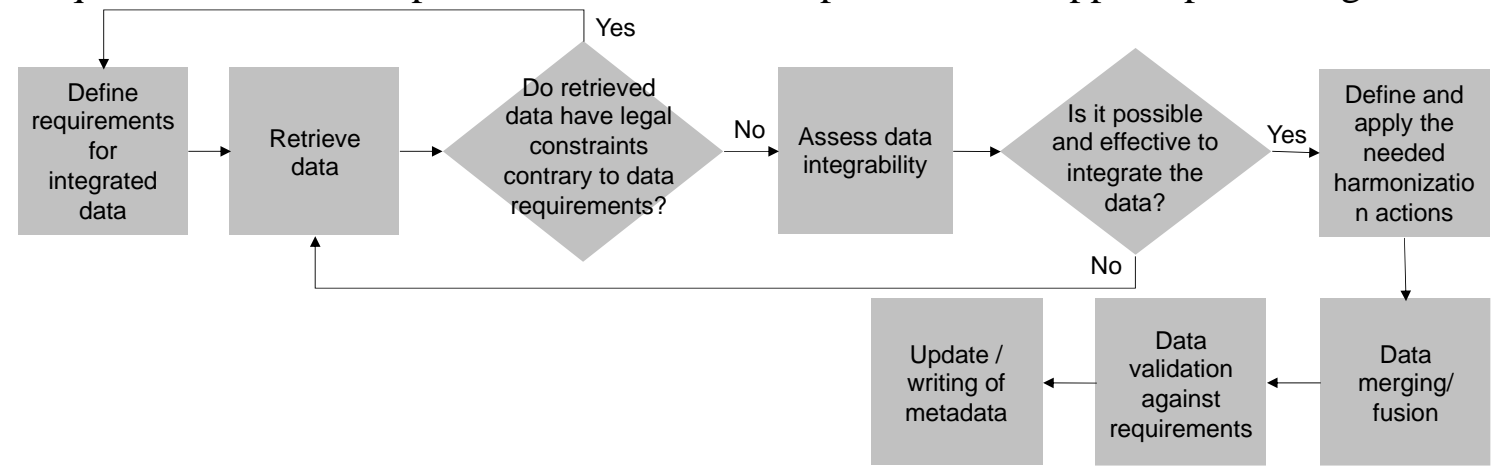

Figure 3. A workflow for suitable data integration

\subsection{Relevant data features and parameters.}

In this section, the data characteristics are explained that should be always explicitly prescribed by data requirements in case of data acquiring and modelling, or harvesting, described in metadata and considered in data integration efforts.

Many resources on spatial data management and integration distinguish between 'semantic' level (i.e. difference in conceptualization and definition - including terms used, specific meaning and classifications); 'structural' or 'schematic' level (i.e. the conceptual model or schema structuring the data - relations between entities and attributes, relationships, hierarchies); and 'syntactical' level (i.e. the format of the data). Semantics and structure are very much interrelated, and one cannot be considered 
without the other. However, they are treated separately here, according to other sources in literature (Doerr, 2004; Kavouras, Kokla 2007; Worboys, Duckham, 2004).

What is generally missing in the literature dealing with data integration theory is the geometry level. Often, this is treated as part of the semantic content of the data, such as in the ontologies-related field (Kavouras, Kokla, 2007). In other studies, geometry is the main focus of integration, like in data fusion and 2D GIS integration literature, but the others are neglected. In this paper, the 'geometric' level is considered as a separated aspect of the data, since it presents specificities which needs to be tackled by means of specific methods.

In addition, more general properties of the data must be considered, related to their contents and intended use, in order to make a preliminary assessment about their usability for the designed goal. These are the geographical extent, time frame and scope. The geographical extent is the location in reality of the objects represented by the data. It is defined by a specific spatial extent located with respect to the Earth surface, which could be 2D (planar location) or 3D (considering heights and $\mathrm{z}$ values). The temporal frame indicates the time period in which data were acquired or updated. The scope of the data is the definition of the part of reality to be represented and the intended use for which the conceptualization was designed. It determines differences with respect to:

- coverage and detail, granularity (e.g. building and building elements vs all city objects);

- classification perspectives and consequent relations (e.g. building door as part of the internal distribution system of the construction vs building door as address);

- semantics, due to the kind of partition of reality, i.e. specific intended meaning of a term or concept, with respect to synonymy, homonymy and different meanings for the same term (e.g. slab intended as structural element or slab intended as all the package dividing the storeys from each other) (Kavouras, Kokla, 2007);

- geometry.

Geographical extent, temporal framework and scope can be documented as objective information. Further, it is relevant to take into account some more qualitative background of the data, which has an impact on modelling and implementation choices, to properly (re)use the data and avoid mistakes in their interpretation.

The original goal of the data (intended use) and the specific use case requirements, for which they are produced, influence the data themselves ('perspective' in Kavouras, Kokla, 2007), affecting the modelling (geometry, semantics, structure) and storage (syntax, data format).

The lineage of the data determines their final characteristics that must be known by the data users (accuracy, objects represented etc.) (e.g., Thapa, Bossler, 1992; Biljecki et al., 2015; Lunetta et al., 1991). It implies modelling method, including the original sources of information possibly processed for the modelling phase (e.g. previous maps, original survey, acquisition and measurement methods, measure processing, storage methods, point clouds, photogrammetric plotting, etc.), the criteria used and the choices made for modelling the final data (represented objects, used LoD, generalization methods and any other pre- or post-processing), Many times, it is sufficient to know the resulting characteristics, but in the most complex cases, documenting the process of production of a dataset can help understand it and use it as properly as possible, avoiding the propagation or generation of errors or misuse and misinterpretation of the data. 
Finally, (software-specific) implementation details - the software that will use the data (or for which/with which the data were modelled) - must be known, since they also determine choices in the use, selection and storage of information within the datasets.

Besides these, Kavouras and Kokla (2007) add, among the causes of taxonomic diversity: discipline (field into which data are designed and generated); ethno-/cultural/socio-based view (nuances in the concept meaning and interpretation of a domain by different cultures or societies, as well as the local geographical terms used); human cognitive diversity (different individuals perceive and conceptualise a domain differently). Therefore, also knowing the authorship of data and the context within which they were generated can help manipulating them correctly. Such diversities are not only relevant for taxonomy, but for the whole bunch of choices made when producing the data, therefore affecting also the geometric modelling, the format chosen and so on. Integration must be aware of all the diversities involved.

Metadata should describe as many as possible of the listed parameters, which are critical to assess the data correctly and speed up the integration, guaranteeing a higher quality of the data resulting from the integration.

Table 1 summarizes the geometric, semantic, structural and syntactical parameters involved in data definition relevant for integration. The rest of this section explains each of such parameters.

Table 1. Synthesis of parameters for data integration potential assessment

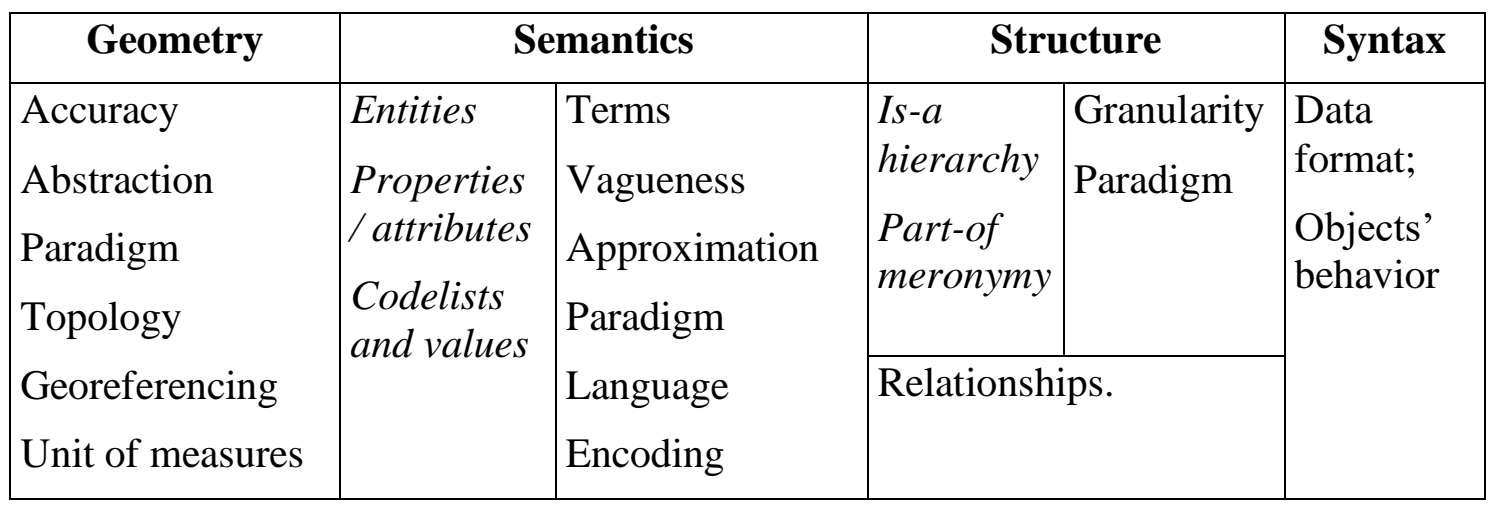

\subsubsection{The geometric parameters}

Geometric accuracy measures the geometries positioning and resolution with respect to the ground reality (Girres, Touya, 2010; Worboys, Duckham, 2004; Laurini, Thompson, 1992).

The level of abstraction corresponds to the concept of cartographic generalization for traditional maps and can be seen as a joint concept of scale and resolution in traditional cartography (Laurini, Thompson, 1992). It allows representing the objects on the map applying the appropriate selection, simplification, symbolization and classification for them to be understandable for a specific scale and a specific purpose (Worboys, Duckham, 2004; Gaffuri, 2011; Stoter et al., 2014, Duchêne et al., 2014). In case of 3D models, the Level of Detail (LoD) concept applies, first defined by CityGML (Gröger, Plümer, 2012; Biljecki et al., 2016). Other kinds of simplification, such as the Level of Development used in Building Information Modelling (Latiffi et al., 2015), are not relevant in this context, since they do not represent an abstraction from a model most faithful to reality, but indicate instead the stage through the path of design and improvement. It should be therefore considered in the retrieval of data phase, 
to assess whether they are suitable to integration, but in case of BIM, the reference from which to abstract more generalised representations should usually be the final design or the as-built BIM.

The same geometry can be represented, modelled and stored following several alternatives or 'paradigms' (raster, vector, implicit, explicit, boundary representation, solid, voxels, etc.). Different modelling options are typical for different types of data, for example, 3D city models usually adopt boundary representation explicit geometries, while BIM uses implicit parametrically modelled geometries (Composite Solid Geometries, swept solids, NURBS, etc.) (Noardo et al., 2020, Arroyo Ohori et al., 2018, Ledoux, 2018). The applications using the geometry for analysis or further processing (i.e., not only for visualization) need specific input. Therefore, depending on the use cases, and as defined accordingly in the data requirements, the data to be integrated must use the same kind of representation and storage of the geometries, in order to be suitably recognised and used properly.

Topology can be within one object, as part of the storage and representation of geometries, and between two objects, as spatial relationships (Ledoux, 2018). These characteristics can have an influence on the use for which the models are intended, as well as other constraints (e.g., Cockcroft, 1997).

Consistent georeferencing is an extremely relevant premise of any integration. It must take into account the used coordinate reference systems, both for planar coordinates (X, Y) and for heights, including: datum, projection, coordinate system, accuracy, and measuring systems (precision, accuracy, reliability, etc.). For example, data acquired with smartphones' GPS sensors or from crowd mapping can have discrepancies with respect to similar data acquired by means of more precise instruments (Dabove, Di Pietra, 2019, Haklay, 2010) that can be relevant depending on use cases.

Unit of measure deals with making the represented objects homogeneous with respect to the scale or precision (Laurini, Thompson, 1992) with which they are represented. In some cases, on-the-fly transformations (e.g., in GIS) allow correct visualization and, more seldom, analysis of the data. However, in most of cases it would be necessary to re-scale the data to a same unit of measure.

\subsubsection{The semantic parameters}

Semantics consists of entities, or classes of represented objects, their attributes and the foreseen values of codelists, which are used in the models. (Relationships between those are covered in the Structure feature),

Attributes are the thematic properties of objects. In turn, they can be represented by different terms and definitions, and can be filled by different values and according to various criteria. Types of values admitted and codelists used - with clear definitions and criteria or methods to use or calculate each value - must be clear. Explaining them with definitions and examples helps understanding the correct intended meaning and avoiding ambiguity.

Entities belonging to different datasets can be compared based on (in ascending analysis depth): the terms used; their definition; their properties and attributes; their instances; relationships.

Moreover, in the description and mapping of entities, attributes and codelist values, it is necessary and analyse the features listed in Table 1: used term, vagueness, approximation, semantic paradigm, language and encoding. 
In some cases, geometric properties, such as spatial relationships and topology, could also be stored as semantics. It is relevant for integration to assess the mode of storage of these characteristics and consider it according to the data requirements definition. It could be in fact necessary to either remove some relationships explicitly stored as semantics (attributes or relationships), whether not necessary in the final data, or calculate and infer them and store them explicitly whether this need is foreseen.

'Term' is the name used to indicate each concept: entity (class), attributes, codelist values (Kavouras and Kokla, 2007), as defined within the ISO25964 (Dextre Clarke, Zeng, 2012, Dextre Clarke, 2011).

'Vagueness' (or 'semantic accuracy') is described by Kavouras and Kokla (2007) as 'the degree of inexactness, fuzziness or indeterminable character of geographic concepts, properties and relationships. Uncertainty, randomness and ignorance contribute to the parameter'. Vagueness refers to the inability to clearly understand the meaning of a concept in a context. Examples of meanings that might not always be clear are 'large', 'high', 'dense'. Storing materials in BIM as just 'wood' or 'glass' can be vague as well for construction-intended purposes.

A different kind of vagueness is related to the source of information. For example, data coming from inferences or enrichment processing of the data will be vaguer than data acquired by survey or authoritative sources.

'Ambiguity', in contrast, is related to the existence of more than one specific meaning, which can be interpreted in different ways. For example, an ifcWall can be either loadbearing or not. There are several ways to understand or specify this, for example, the specific attribute can be used, or it can be assessed based on the disciplinary model being considered (whether structural or architectural, for example). Other examples can be in the interpretation of aerial imagery, whether green roofs are represented, which can be interpreted as grass field, and similar cases. It can be solved by specifying the context. Context (Kavouras, Kokla, 2007) is the restricted conceptual milieu giving meaning to the concept expressed. In the data models, it is usually described in the definition of each term/entity/class. Constraining the interpretation of each description, likely with examples, is also important to obtain consistent data.

'Approximation' (or 'semantic abstraction level') has to do with the granularity of the conceptualization and the level of detail reached by the semantic description.

'Semantic paradigm' is the reference reality and perspective for the conceptualization of the semantic representation of the data (Klein, 2001; Kavouras and Kokla, 2007). Within this feature, we can also include the criteria used to fill the attribute values or methods to be used to calculate them, as well as the unit of measure used.

National language used is relevant (English, Italian, Dutch, French...), as well as the encoding of the terms and values for entities, attributes and codelists (Klein, 2001). For example, the use of uppercase or lowercase letters and punctuation; storage of dates as $\mathrm{dd} / \mathrm{mm} / \mathrm{yyyy}$ or $\mathrm{mm} / \mathrm{dd} / \mathrm{yyyy}$; codelists referring to a code (e.g. a number or an alphanumerical string) or containing the value directly, and so on.

\subsubsection{The structural parameters}

The structure, or schema, of thematic information is described in the data model or the ontology followed by the data. Although being slightly different artifacts (Spyns et al., 2002), the principles and features on which the integration of data models or ontologies depends can be considered similar. 
Ontology science (e.g., Kavouras, Kokla, 2007; Mostafavi, 2006) provides useful tools and theory with respect to data structure integration. In some cases, the foreseen situations for ontology integration are more complex than what is usually found in data models structuring data from practice (for example multiple inheritance is hardly present, or impossible, in data from practice). However, the concepts formulated can be reused to guide the integration of different semantic structures.

Semantic 'relationships' among two or more concepts include dependencyassociation (Kavouras, Kokla, 2007). The 'is-a hierarchies' must be considered, including the distance of a node (a concept) from the root of the ontology or data model and possible multiple inheritance. Similarly, 'part-of meronymic hierarchies' are relevant to assess similarity of two structures.

'Granularity', intended as the smallest and biggest objects represented is the parameter useful to compare different data structures, together with the 'paradigm' according to which the reality is interpreted and conceptualized in the data schema. The two parameters must be considered for both the is-a hierarchies and the part-of meronymies.

3.1.3.4 A reflection on (Open) standard-compliant data. Structure, as well as semantics and geometry, can be declared compliant to (Open) standard data models. However, this does not solve the harmonization-related issues, since many data from practice can implement or interpret the standard data models differently (Section 1.1). In addition, a few variables must be taken into account.

First, the version of the standard must be checked. Although in theory backwards compatibility should be guaranteed, new versions may dismiss part of the schema or introduce new classes, attributes and codelists. New specifications may constrain the use of the standard. As a result, data may result different from data compliant to previous versions. For example, in the CityGML version n. $3^{9}$, entirely new modules are introduced with respect to version n.2 (OGC, 2012) ${ }^{10}$, such as 'Construction', to describe construction details, as well as other modules related to the performance of the model, like 'Versioning' and 'Dynamizer'. Other changes are made in the core module, introducing the concept of 'FeatureType' (i.e. abstractions of realworld phenomena that have an identity) disjoint from 'ObjectType' (i.e. objects that have an identity but are not features). It makes the general conceptualisation quite different from the previous version, and compliant models can therefore differ over different versions of the same standard accordingly. The concept of space was mainly modelled by 'Room' class in CityGML 2, while there is a different and more detailed conceptualisation foreseen in version 3 (AbstractLogicalSpace, AbstractPhysicalSpace, occupied or unoccupied space and so on).

Another example, among many others, is the storage of georeferencing information in IFC v. $2 \times 3$ with respect to v.4, where the storage of more complete information is enabled (Clemen, Görne, 2019).

Besides that, often not the entire standard data model is used in datasets, but only a profile, that is a part of the entire model, according to the needs of applications. It represents the actual data model used by the data and it is therefore relevant to outline it explicitly. The description of the specific interpretation and use of the model is very relevant to enable consistent use and integration.

\footnotetext{
${ }^{9}$ https://docs.ogc.org/is/20-010/20-010.html [Accessed 24 $4^{\text {th }}$ November 2021]

${ }^{10}$ https://www.ogc.org/standards/citygml [Accessed 24th November 2021]
} 
Similarly, extensions of the standard data models are used to enhance their representation scope for specific applications, by means of foreseen mechanisms, such as the Application Domain Extension (ADE) in CityGML (Van den Brink et al., 2013b). In case official extensions are used, they can be considered similar to a reference data model themselves, therefore, the version and used profile must be verified and compared as well.

Moreover, generics (classes, attributes and relationships) are foreseen in the standard data models ('generics' module in CityGML, ifcProxies in IFC). They provide a structure for objects not covered by any other class, attribute or relationship in the standard conceptual model. Although the recommendation is to use them only if an appropriate structure is not provided by the rest of the schemas, in data from practice they are very often used in place of existing entities. Therefore, even if standardcompliant, many data follow a customized data model (Noardo et al., 2021b; Colucci et al., 2020).

Such variations of standard data models (profile, extension, use of generic classes) should be documented in proper metadata and documentation associated to the dataset, including, preferably, the formal encoding and the parameters described in this Section (3.1). It would enable the almost automatic mapping and conversion of compliant datasets. However, most of datasets coming from practice do not document this explicitly and it is necessary to analyse the data manually.

Additional variability could come from different interpretations of the same data model. A translation or conversion or even enrichment / new acquisition can be necessary whether the interpretation of the data model is too far from data requirements.

Adopting Open standards, even if using different profiles and extensions, would give the advantage of speed-up the mapping to support the following assessments.

\subsubsection{The syntactical parameters}

For the syntactic level, the 'format' encoding the data is relevant (e.g., GML, JSON, STEP, TIFF, shapefile, ASCII and so on), including the version of the implementation languages used and all the conditions and choices possibly adopted.

'Objects' behaviour' (in object-oriented spatial databases, operations and axioms that define them) (Egenhofer, Frank, 1992) is also amongst the features relevant for integration, although models from practice hardly reach such complexity.

\subsection{Define requirements for the integrated data}

As when modelling new data sets, to obtain proper data for the desired application and use case, data requirements for the data to be integrated must be defined. Some standards propose guidelines to define data requirements properly, for example in the building and civil engineering works domain, the concept of Level Of Information Need is established by the ISO 19650-1:2018 ${ }^{11}$ for information stored in BIM. Meanwhile, buildingSMART defines the Information Delivery Specification (IDS) standard to define the exchange requirements in a computer interpretable format, to define the

\footnotetext{
${ }^{11}$ https://www.iso.org/obp/ui/\#iso:std:iso:19650:-1:ed-1:v1:en [Accessed 24 $4^{\text {th }}$ November 2021]
} 
Level of Information Need and allowing data validation ${ }^{12}$. In the geospatial domain, data requirements must also be defined, according to the use case for which they are intended (Malinowski, Zimányi, 2006).

It is essential to define such data requirements as well for the information resulting from integration, considering the mentioned standards and covering all the parameters listed in Section 3.1. They will later guide all the following steps of the integration (data retrieval, information selection, harmonization and processing and data merging/fusion/combining).

In data requirements, tolerance thresholds can also be set to establish the admitted discrepancy with respect to the defined parameters.

\subsection{Data retrieval}

In this paper we will not analyse the issues related to data retrieval (findability, usability, licenses, costs and so on). However, this does represent a further aspect to be considered in the integration. The legal and policy constraints must be checked against the possibility to use the data for integration and the data requirements (including foreseen use and publication of the data and so on).

If any technical (e.g., the necessary information is not present or not suitable) or non-technical (e.g., costs, licence, etc.) issue is found, a new data retrieval phase is necessary.

Data retrieval include both existing datasets and possible new acquisitions, whether it is not possible to find any suitable resource.

\subsection{Pre-assessment of data integrability}

A preliminary assessment about the effectiveness of data sets integration can be performed by comparing initial information about the geographical extent, time frame and scope (Figure 4). Scope will be later specified as the geometry, semantics and structural characteristics described in Section 3.5. The preliminary information could be found in good metadata, otherwise it will be necessary to retrieve it, whether possible, by inspecting the data or annexed documentation.

\footnotetext{
${ }^{12}$ https://technical.buildingsmart.org/projects/information-delivery-specification-ids/ [Accessed $24^{\text {th }}$ November 2021]
} 

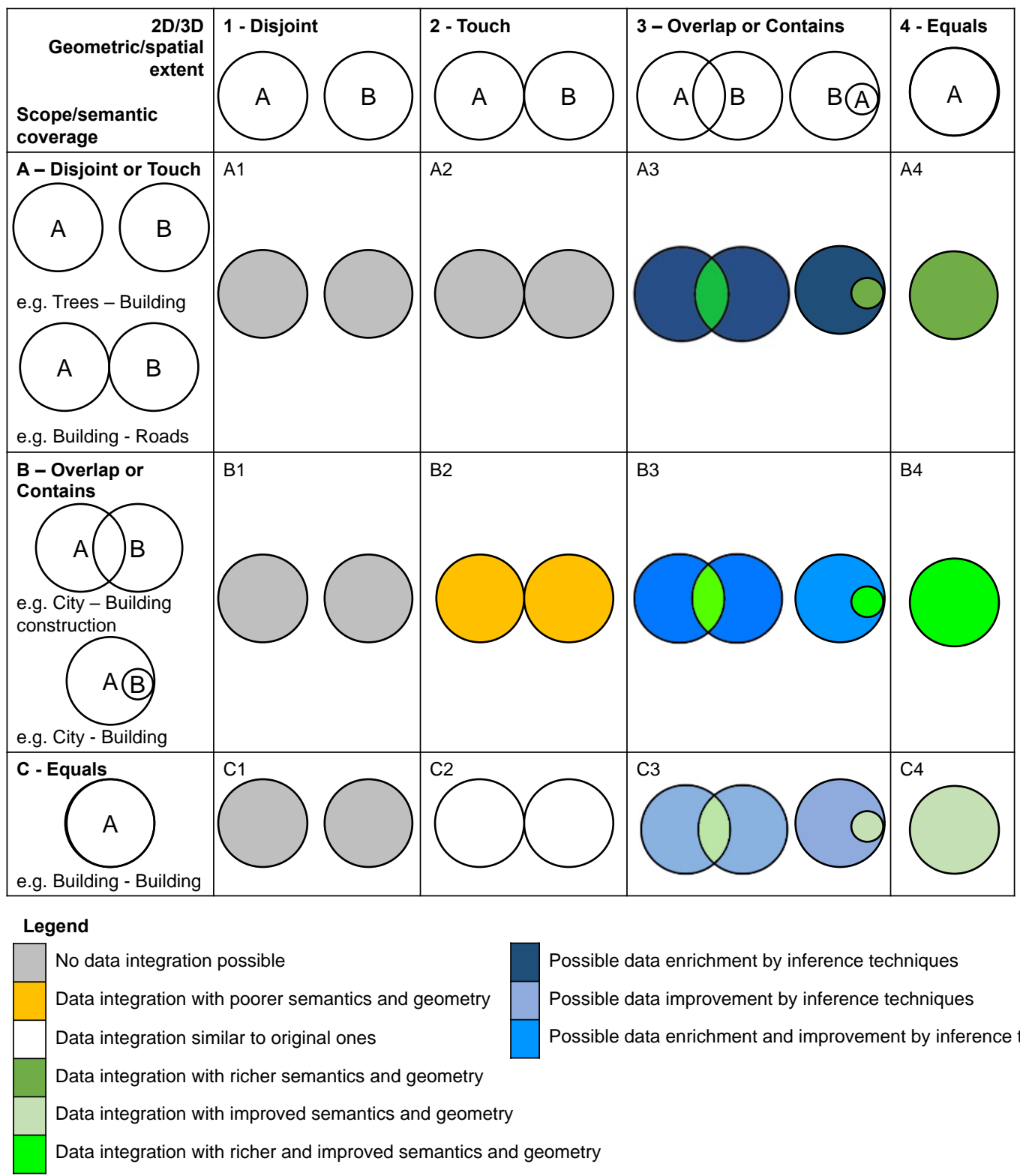

Figure 4. Overview of the possible data integration based on the spatial and logical relationships of geographical extent and scope/semantic coverage.

Examples of datasets covering different scopes and semantic coverage are: A - any 3D city model (A) and weather data related to sensors represented in a map (B); B - a 3D city model or map (A) and a BIM (B) or a 2D digital map (A) and a CityGML model containing only buildings, as there are many examples; $\mathrm{C}$ - two CityGML models (e.g. Figure 1).

In cases A1, A2, B1, C1, in Figure 4, it does not make sense to integrate the data, unless by trying with complex inferences and machine learning or data mining processing (e.g. Perumal et al., 2015; Wang, 2017; Sheeren, 2004). In A3 and A4 the overlapping area can be integrated to obtain a richer dataset.

In the B2 case, data can be integrated to obtain a more extended dataset with the overlapping semantic coverage of the two datasets. In B3 and B4, the overlapping area can be integrated to obtain a richer dataset by integrating the information related to different semantic coverage, while the overlapping semantic coverage of the two 
datasets can be used to improve the quality of the data through the integration, by mapping and comparing the data and selecting the better or most suitable version of the information.

In C2, data can be integrated to obtain a similar dataset on a wider extent. Mapping and information quality comparison can help checking consistency on the final data (slightly improved or decreased depending on details of the harmonisation processing).

In $\mathrm{C} 3$ and $\mathrm{C} 4$, in the overlapping areas, the two datasets should be quite similar. Still, they could differ for the geometric representation or differences in data quality, which would make the integration useful to improve the data through mapping and information quality comparison.

In A3, B3 and C3 cases, inferences techniques can be assessed for enriching the data in the non-overlapping area based on the integration processing on overlapping part.

B1 and C1 could be similar to the B2 and C2 cases, respectively. However, the two datasets could be successfully harmonised and converted to a common format, but the final step of data merging/fusion or combining would not make sense. It must be decided based on use cases whether the effort is useful.

Additional discussion would be necessary about the use of data referring to different time frameworks. In this case, whether the spatial extents overlap at least in part (cases 3 and 4 in Figure 4), and the scope and kind of representation as well (cases $\mathrm{B}$ and $\mathrm{C}$ in Figure 4), the data could be integrated for the overlapping part, at least, if setting the priorities and criteria for merging based on the data requirements. Optimal case would be using data referred to close time frameworks.

\subsection{Detailed assessment of data integrability}

It is necessary to run a preliminary data quality assessment with respect to the defined data requirements, to answer the question: 'Is it appropriate and effective to integrate the data?'. For some of the parameters considered, there are quality thresholds deciding the suitability of the dataset (e.g. the minimum accuracy), while in other (most of) cases, the data can be improved through pre-processing in order to reach the needed quality.

In this case as well, metadata and annexed specifications should be analysed first, to speed up the process whether they report suitable and reliable information.

Tables 2,4,5,6 define a rubric to assess the level of integrability of datasets, i.e., their compatibility with respect to the data requirements prescribed and the needed preprocessing. Based on the data requirements, availability of alternative data, effort required and processing options, the user will assess the suitability of the data to be involved in the integration or whether a different choice of data (including new acquisition and processing) should be preferred. In the tables, scores are given based on the scale: 0 - the data cannot be used for integration; 1 - the data must be pre-processed through complex data mining/machine learning/ data enrichment processing; 2 - the data must be pre-processed to be generalised properly; 3 - a conversion must be applied; 4 - the data can be used as they are.

\subsubsection{Geometry integrability assessment}

Table 2 explains the criteria to assess geometry-related parameters. Regarding 
'accuracy', on the condition that both datasets respect the minimum accuracy required, there are no studies demonstrating specific issues when integrating datasets having different accuracies. Although it is preferable the two datasets having similar accuracy, it is possible to consider valid a dataset coming from two datasets having different accuracies as well. However, future studies will investigate the issue in more detail, to identify possible challenges and thresholds in the difference of accuracy between the datasets involved in the integration.

A minimum condition for georeferencing also applies. Georeferencing information, with the minimum accuracy required by data requirements, can be later converted or inferred, but an indication of georeferencing parameters, reference points or at least a qualitative description about the data location is necessary.

Table 2. Level of integrability based on the geometry-related parameters.

\begin{tabular}{|c|c|c|c|c|c|}
\hline & 0 - not usable & 1 - enrichment & 2 - generalization & 3 - conversion & $4-$ as is \\
\hline 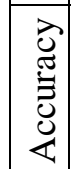 & $\begin{array}{l}<\text { data } \\
\text { requirements } \\
\text { accuracy }\end{array}$ & - & - & - & \begin{tabular}{|l}
$\geq$ data \\
requirements \\
accuracy
\end{tabular} \\
\hline 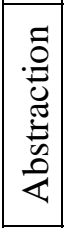 & $\begin{array}{l}\text { The needed } \\
\text { objects are not } \\
\text { represented }\end{array}$ & $\begin{array}{l}\text { Represented } \\
\text { objects need } \\
\text { more details for } \\
\text { a higher LoD or } \\
\text { higher-resolution }\end{array}$ & $\begin{array}{l}\text { Geometries must } \\
\text { be generalised to } \\
\text { a lower LoD or } \\
\text { lower resolution }\end{array}$ & - & $\begin{array}{l}\text { Same than } \\
\text { prescribed in } \\
\text { data } \\
\text { requirements }\end{array}$ \\
\hline 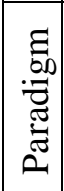 & - & - & - & $\begin{array}{l}\text { Geometries must } \\
\text { be converted to a } \\
\text { different } \\
\text { representation }\end{array}$ & $\begin{array}{l}\text { Same than } \\
\text { prescribed in } \\
\text { data } \\
\text { requirements }\end{array}$ \\
\hline $\begin{array}{l}\text { ते } \\
0 \\
0 \\
0 \\
0 \\
\end{array}$ & $\begin{array}{l}\text { Topological } \\
\text { relationships } \\
\text { stored as } \\
\text { prescribed by } \\
\text { requirements } \\
\text { cannot be } \\
\text { seen/inferred }\end{array}$ & $\begin{array}{l}\text { Topological } \\
\text { relationships can } \\
\text { be inferred }\end{array}$ & $\begin{array}{l}\text { Topological } \\
\text { relationships can } \\
\text { be generalised }\end{array}$ & $\begin{array}{l}\text { Topological } \\
\text { relationship must } \\
\text { be expressed in a } \\
\text { different way. }\end{array}$ & $\begin{array}{l}\text { topological } \\
\text { relationships } \\
\text { stored as } \\
\text { prescribed by the } \\
\text { data } \\
\text { requirements }\end{array}$ \\
\hline $\begin{array}{l}0 \\
: \\
0 \\
0 \\
0 \\
0 \\
0 \\
0 \\
0 \\
0 \\
0 \\
0\end{array}$ & $\begin{array}{l}\text { No information } \\
\text { about location }\end{array}$ & $\begin{array}{l}\text { Little, vague, } \\
\text { inaccurate } \\
\text { information (e.g. } \\
\text { address or a } \\
\text { description) }\end{array}$ & - & $\begin{array}{l}\text { Information is in } \\
\text { a different CRS } \\
\text { or stored } \\
\text { differently than } \\
\text { prescribed in } \\
\text { requirements }\end{array}$ & $\begin{array}{l}\text { CRS, accuracy } \\
\text { and storage as } \\
\text { prescribed in } \\
\text { data } \\
\text { requirements }\end{array}$ \\
\hline 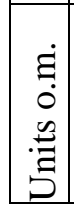 & - & - & - & $\begin{array}{l}\text { The model must } \\
\text { be scaled and/or } \\
\text { converted to a } \\
\text { different unit }\end{array}$ & $\begin{array}{l}\text { Same than } \\
\text { prescribed in } \\
\text { data } \\
\text { requirements }\end{array}$ \\
\hline
\end{tabular}

\subsubsection{Semantics integrability assessment}

Semantics consist in the concepts expressed by objects names, as well as by the terms defining attributes and composing code lists. Those should be described within proper definitions, removing possible ambiguity from interpretations. 
Considering both terms and definitions while mapping the concepts and objects represented in two different data sets allows a higher reliability in the similarity assessment (Table 3), as well as considering their features and semantic neighbourhood and context (Rodríguez, Egenhofer, 2003; Kavouras, Kokla, 2007). The reliability of the mapping still increases when considering attributes and instances as well. In case of geographical datasets, the spatial dimension of instances can also be used to establish correspondence between features (Rodríguez, Egenhofer, 2003).

Table 3. Different combination of Term (T) and Definition (D) cases (Kavouras, Kokla, 2007)

\begin{tabular}{|c|c|c|}
\hline & 1) $\mathrm{T} 1=\mathrm{T} 2$ & 2) $\mathrm{T} 1 \neq \mathrm{T} 2$ \\
\hline a) D1=D2 & a1) Equivalence & a2) Synonymy \\
\hline b) D1>D2 & $\begin{array}{l}\text { b1) Further investigation } \\
\text { required }\end{array}$ & b2) IS-A \\
\hline c) $\mathrm{D} 1 \cap \mathrm{D} 2$ & c1) Overlap & c2) Overlap \\
\hline d) $\mathrm{D} 1 \neq \mathrm{D} 2$ & d1) Homonymy & d2) Disjointness \\
\hline
\end{tabular}

Terminological-conceptual conflicts can be: 'confounding' - information items having deceptively the same meaning but are actually differing (e.g. a 'tie-beam' was interpreted as 'IfcBeam' in an example reported by Noardo et al., 2022); 'scaling' from the use of different reference systems and scale; 'naming' - from using different terms (homonyms and synonyms) (Kavouras, Kokla, 2007; Wahe et al., 2001).

The possibility to convert between different semantics paradigms, including between different calculation methods and filling criteria for attributes, should be assessed for the specific cases: e.g. calculation could be based on further data or values that must be known etc. Condition is that the semantic paradigm, filling criteria and methods used are well documented within metadata.

The semantic paradigm must be compatible with the data requirements. For example, Noardo et al. (2016) reports differences in filling the roads classification in Italian and French digital maps, being 'paved'/ 'unpaved' in the Italian maps and classified according to a hierarchy of functions in the French maps. In this case, it is hard to infer or calculate the values from the available data, and a third source of information is likely necessary.

Table 4. Level of integrability based on the semantics-related parameters. Each parameter must be taken into account for: entities; properties and attributes; codelists values and attribute values.

\begin{tabular}{|c|c|c|c|c|c|}
\hline & 0 - not usable & 1 - enrichment & 2 -generalization & 3 - conversion & $4-$ as is \\
\hline E्己 & $\begin{array}{l}\text { Cases d) } \\
\text { (Table 3) }\end{array}$ & $\begin{array}{l}\text { Cases b), } \\
\text { definition of } \\
\text { data is larger } \\
\text { than definition } \\
\text { in requirement; } \\
\text { Cases c) partial } \\
\text { information is } \\
\text { present in data }\end{array}$ & $\begin{array}{l}\text { Cases b), } \\
\text { definition of } \\
\text { data is } \\
\text { narrower than } \\
\text { definition in } \\
\text { data } \\
\text { requirement }\end{array}$ & $\begin{array}{l}\text { Case a2) - } \\
\text { synonymy }\end{array}$ & $\begin{array}{l}\text { Case a1) - } \\
\text { equivalence }\end{array}$ \\
\hline
\end{tabular}




\begin{tabular}{|c|c|c|c|c|c|}
\hline 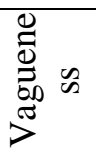 & $\begin{array}{l}\text { > data } \\
\text { requirements' } \\
\text { vagueness }\end{array}$ & - & $\begin{array}{l}\text { Data can be } \\
\text { generalized. }\end{array}$ & - & $\begin{array}{l}\leq \text { data } \\
\text { requirements' } \\
\text { vagueness }\end{array}$ \\
\hline 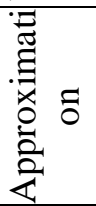 & $\begin{array}{l}\text { The needed } \\
\text { objects are not } \\
\text { represented }\end{array}$ & $\begin{array}{l}\text { Lower } \\
\text { approximation } \\
\text { needed by data } \\
\text { requirements }\end{array}$ & $\begin{array}{l}\text { Higher } \\
\text { approximation } \\
\text { needed by data } \\
\text { requirements }\end{array}$ & - & $\begin{array}{l}\text { Same than } \\
\text { prescribed in } \\
\text { data } \\
\text { requirements }\end{array}$ \\
\hline 急 & Incompatible & - & - & Compatible & Same \\
\hline 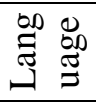 & - & - & - & $\begin{array}{l}\text { Different } \\
\text { language }\end{array}$ & Same language \\
\hline 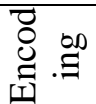 & - & - & - & $\begin{array}{l}\text { Different } \\
\text { encoding }\end{array}$ & Same encoding \\
\hline
\end{tabular}

\subsubsection{Structure integrability assessment}

Table 5 defines the criteria to assess the integrability of data based on the structural parameters.

Table 5. Level of integrability based on the structure-related parameters.

\begin{tabular}{|c|c|c|c|c|c|c|}
\hline & 0 - not usable & 1 -enrichment & $\begin{array}{c}2- \\
\text { generalization }\end{array}$ & 3 - conversion & $4-$ as is \\
\hline \multirow{2}{*}{ 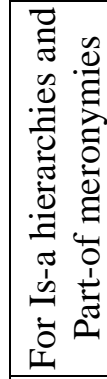 } & 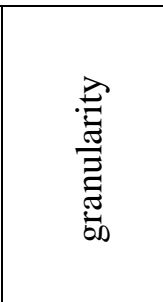 & $\begin{array}{l}\text { The needed } \\
\text { objects are } \\
\text { not. } \\
\text { represented }\end{array}$ & $\begin{array}{l}\text { Higher } \\
\text { specification } \\
\text { and deeper } \\
\text { hierarchy } \\
\text { needed by } \\
\text { requirements }\end{array}$ & $\begin{array}{l}\text { Lower } \\
\text { specification. } \\
\text { shallower } \\
\text { hierarchy } \\
\text { needed by } \\
\text { requirements }\end{array}$ & - & $\begin{array}{l}\text { Same than } \\
\text { prescribed } \\
\text { by data } \\
\text { requirement } \\
\text { s }\end{array}$ \\
\hline & Paradigm & Incompatible & - & - & Compatible & Same \\
\hline \multicolumn{2}{|c|}{ Relationships } & $\begin{array}{l}\text { Absent and } \\
\text { not inferable }\end{array}$ & $\begin{array}{l}\text { Relationship } \\
\text { s can be } \\
\text { inferred }\end{array}$ & $\begin{array}{l}\text { Relationships } \\
\text { can be } \\
\text { generalized }\end{array}$ & $\begin{array}{l}\text { Relationship } \\
\text { s (names, } \\
\text { encoding, } \\
\text { criteria) can } \\
\text { be converted }\end{array}$ & $\begin{array}{l}\text { Same than } \\
\text { prescribed } \\
\text { by. data } \\
\text { requirement } \\
\text { s }\end{array}$ \\
\hline
\end{tabular}

\subsubsection{Syntax integrability assessment}

Table 6 defines the criteria to assess the integrability of data based on the syntactical parameters.

Table 6. Level of integrability based on the syntactic-related parameters.

\begin{tabular}{|l|l|l|l|l|l|}
\hline & $0-$ not usable & $\begin{array}{c}1- \\
\text { enrichment }\end{array}$ & $\begin{array}{c}2- \\
\text { generalization }\end{array}$ & $\begin{array}{c}3- \\
\text { conversion }\end{array}$ & \multicolumn{1}{|c|}{4 as is } \\
\hline $\begin{array}{l}\text { Data } \\
\text { format }\end{array}$ & - & - & - & $\begin{array}{l}\text { Data formats } \\
\text { are different }\end{array}$ & $\begin{array}{l}\text { Same data } \\
\text { format }\end{array}$ \\
\hline
\end{tabular}




\begin{tabular}{|l|l|l|l|l|l|}
\hline $\begin{array}{l}\text { Objects' } \\
\text { behaviour }\end{array}$ & $\begin{array}{l}\text { Needed } \\
\text { objects' } \\
\text { behaviour } \\
\text { are not } \\
\text { present }\end{array}$ & $\begin{array}{l}\text { Objects' } \\
\text { behaviours } \\
\text { must be } \\
\text { added }\end{array}$ & $\begin{array}{l}\text { Objects' } \\
\text { behaviours } \\
\text { must be } \\
\text { removed }\end{array}$ & $\begin{array}{l}\text { Objects' } \\
\text { behaviours } \\
\text { must be } \\
\text { converted }\end{array}$ & $\begin{array}{l}\text { Same } \\
\text { objects' } \\
\text { behaviours }\end{array}$ \\
\hline
\end{tabular}

\subsubsection{The final overall assessment}

The integrability potential of the dataset can be roughly measured by summing up the scores related to all the parameters considered and reported by data requirements. If any of the parameters has scored 0 , the integration cannot be performed and the process should be blocked. The maximum integrability rate is the total number of parameters, calculated as in equation: number of involved parameters $* 4$ (i.e., all the parameters scored 4 and the data set can be merged as is), while the minimum should be the total number of parameters (all the parameters scored at least 1, i.e., the dataset can be used after an enrichment that is possible). However, this is only a rough assessment, and the processing to harmonize the dataset with respect to each parameter needs to be considered singularly.

Moreover, it should be noticed that the assessment can regard only the part of the data set which is intended to be used in the integration. On the other hand, some of the parameters can be not relevant for the data requirements (e.g., there are no attributes or code lists). Checking that all the information prescribed in data requirements is covered by the datasets involved in the integration must be done separately, in the initial phase of data retrieval and/or later, during the validation step.

\subsection{Define the processing to solve the inhomogeneities pointed out by the}

\section{integration assessment.}

Once the data sets involved are assessed as suitable for the integration (integrability scores 1 to 3 as defined in Section 3.5), a pre-processing must harmonize their characteristics with the ones indicated by data requirements (to reach integrability score 4). In this section, the needed actions are listed, together with possible methods, referring to each parameter and integrability score case. The Subsection 3.6.1 introduces the semantic and structure mapping, as defined within the ontology engineering field. It is preliminary to understand the suggested approach in processing and harmonizing the data in this paper.

\subsubsection{Ontologies and data models mapping and integration}

The 'schema mapping', or 'schema matching' (implying also semantics) is the definition of an automated transformation of each instance of a data structure A into an instance of a data structure B that preserves the intended meaning of the original information (Doerr, 2004). The preservation of the intended meaning must be ultimately judged by the application domain expert.

Doerr (2001) defines the principles for mapping thesaurus terms by means of concept-based mapping. Mapping and ontology integration techniques are the tools necessary to solve most of the inhomogeneities in semantics, in 'Terms' choice, and in the structure. For this reason, although each parameter is considered as a separated issue 
in this paper, for not neglecting any of them, a mapping between the classification followed by the input data and the one defined by the data requirements is the preliminary step to guide the following processing to harmonise the semantics and structure features.

The techniques and methodologies for mapping different data models or ontologies consider schematic and semantic differences, including syntactic and semiotic/pragmatic heterogeneities in some cases (Kavouras, Kokla, 2007). There are several approaches to integrate ontologies, many of which are based on inter-ontology mapping and alignments between multiple ontologies (Wahe et al., 2001).

According to Kavouras and Kokla (2007), ontology integration approaches can be defined according to three dimensions: D1) the possible change/alteration/distortion caused; D2) the number of ontologies resulting from the integration process; D3) the use of a target ontology in the integration process. For the scope of this paper, an integration involving possible change/alteration/distortion is admitted (D1), one only data model will result from the integration (D2) and the ontology or data model defined in the data requirements will be used as target (D3). The destination data model or ontology could correspond with one of the involved data sets schemas or being a third one defined by data requirements. A hybrid approach (Wahe et al., 2001) is the recommended one (Figure 5).

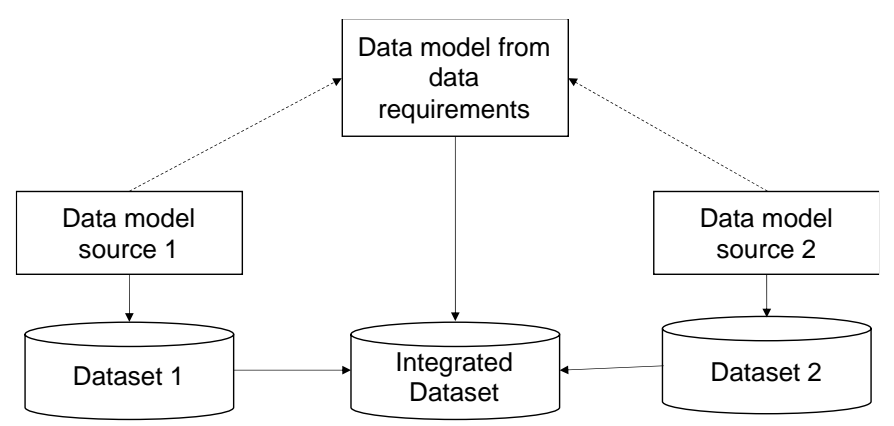

Figure 5. Recommended integration approach in this paper.

Ontology integration consists of (the iteration of) the following steps (McGuinness et al., 2000; Klein, 2001):

(1) Matching, i.e., the procedure that compares concepts and matches those that are more similar in meaning according to a given context (Kavouras, Kokla, 2007; Klein, 2001), or find where the two conceptualizations overlap (McGuinness et al., 2000; Klein, 2001);

(2) Alignment to be generated accordingly (Osman et al., 2021), i.e., mapping of correspondences (equivalence or subsumption relation) between concepts in two or more ontologies into mutual agreement (Kavouras, Kokla, 2007) making them consistent and coherent (Klein, 2001), to overcome syntactic (representation format), terminological (naming differences), conceptual (coverage, granularity and perspective) and semiotic/pragmatic (how the ontology is interpreted or used by communities with respect to a context) heterogeneities (Wahe et al., 2001).

(3) Merging or integrating ontologies is defined as the creation of a new ontology from two or more existing ontologies with overlapping parts, which can be either virtual or physical (Klein, 2001). Osman et al. (2021) define and analyse 
in more detail the types of processes that can be involved in the abovementioned cases, as a useful reference for semantic integration processes.

(4) Check the consistency, coherency and non-redundancy of the result.

For the aims of this paper, the generation of a new ontology (step 3) is not of interest, but rather, the mapping will be useful to determine the selection, interpretation and processing to convert the semantics and structure of the input datasets into the ones defined within the data requirements.

\subsubsection{Harmonization of the geometry}

Accuracy. There is no needed pre-processing to adjust the accuracy, since it is a simple threshold value (either sufficient or not).

Depending on the use cases, it can be assessed case by case whether it is necessary to add acquisition uncertainty to possibly too accurate data. For example, the method proposed by Biljecki et al. (2015) can be used. However, there is no evidence, at the moment, showing that excessively accurate data could bring issues to the integration process.

Similarly, there is no proved research so far showing a reliable method to improve data accuracy without new acquisitions. Some studies propose to improve accuracy by referring to a reliable existing dataset (Noskov, Doytsher, 2017). It could be considered case by case if a similar approach could be applied and what does it entail in $3 \mathrm{D}$.

Abstraction level. Either enrichment or generalization can be necessary.

1 - enrichment) Enrichment is the process of adding missing details to the data in order to increase the amount of information contained. It could use simple processing derived from information contained in the data themselves. For example, the building footprints could be extruded until the height values stored as attribute in the same dataset. Another case foresees the use of external sources to get the necessary information to generate higher levels of detail models. For example, to extrude building footprints using Digital terrain models and heights point clouds as references (Ledoux et al., 2021). More advanced techniques can consider machine learning or other kinds of inferences to complete the unknown information (Biljecki, Dehbi, 2019; Park, Guldmann, 2019)

2 - generalization) Generalization can be applied in case the source data are too detailed. Depending on the kind of data, it means resampling the raster data, reducing detail in the vector data. Studies on generalization are many, some of which are reviewed by Geiger et al. (2015). For 3D city models, for example, it implies extracting lower Levels of Detail from higher LoD representations. Some examples are given by Diakité et al. (2014), Guercke, Brenner (2009), Baig, Abdul-Rahman (2013a,b).

Another case is the generalization of BIMs into 3D city models representations, which imply both a change in the representation paradigm and storage of geometry, and a generalization (Geiger et al., 2015; Donkers et al., 2016; Sun et al., 2019).

In the case of generalization of 3D information systems, including 3D city models, BIM and similar ones, two operations must be considered, i.e., feature extraction, selecting the objects and features to be considered to compute the generalized geometry, and the generalization itself (Guercke, Brenner, 2009). The phase of feature extraction can be based either on geometry (e.g., topological relationships, 
distance-based or bounding box criteria) or semantics (e.g. including or excluding specific classes of objects, or selecting objects based on attributes - such as the 'isExternal' attribute in IFC).

Geometric paradigm. The harmonization of the geometric paradigm is done via conversion.

3 - conversion) In this case the geometries must be converted into a different representation, as defined by data requirements, for example by means of ETL tools (Noardo et al., 2020).

Topology. Data requirements should specify the kind of topological information needed and the kind of storage of such information. Moreover, a validation procedure should be indicated or developed to check that topology is correctly used both in the storage of geometries and in the reciprocal objects' relationships.

1 - enrichment) Data mining, machine learning and inferences techniques (Krijnen et al., 2020) can be used to infer and store a richer topology. Manual techniques could be considered as well in some cases.

2 - generalization) Topological relationships can be generalised to comply with more abstract representations (e.g. Egenhofer et al., 1994).

3 - conversion) The kind of storage of such relationships (being them implicit or explicitly stored in the models) must also be maintained and made compliant to the data requirements (Diakité et al, 2014; Vitalis et al., 2019, Jun, 2019, Zhao, Mbachu, 2019; Salheb et al., 2020).

Georeferencing. It implies the Coordinate Reference System (CRS) for planar coordinates and heights, accuracy of the georeferencing and kind of storage of georeferencing parameters.

1 - enrichment) Techniques to infer the correct georeferencing from too vague data (e.g. the address) can be considered. Options include comparing the model to a different spatial representation (e.g. a BIM model to the parcel where it is supposed to lie, the representation of the model in its context in non-interoperable format, such as PDFs) or a manual positioning based on qualitative information and description. Other inference techniques can be assessed in order to automate the processing (e.g. Hiebel at al., 2017).

3 - conversion) Re-project to the coordinate and height system prescribed by the data requirements. Techniques can vary based on the kind of data being georeferenced (Noardo et al., 2016; Uggla, Horemuz, 2018; Jaud et al., 2020).

Unit of measure. A simple conversion can harmonize the unit of measure used.

3 - conversion) The geometries should be scaled to the unit of measure needed by the data requirements. ETL tools as well as other modelling software allow this.

\subsubsection{Harmonization of the semantics}

Terms and definitions. For the three cases of enrichment (1), generalization (2) and conversion (3), a mapping (Section 3.6.1) must be applied, after having measured and analysed similarity. 
Mapping can be done automatically, semiautomatically or manually. Machine learning techniques can also be used (e.g. Doan et al., 2004).

Vagueness. As for the geometric accuracy case, the semantic data should be no vaguer than what admitted by data requirements. It is not possible to enrich the data, because, even if adding more detail starting from the data themselves, the original vagueness would be propagated without reaching the objective.

2-generalization) In case of more accurate data, it is not necessary to consider any processing. In some cases, it is possible that a vaguer value is necessary, for example, a classification 'high', 'medium', 'low', rather than the exact measurement. In such cases, a processing should be applied (and tracked in metadata) to compute and classify the values.

Approximation. As for the case of geometric abstraction level, either enrichment or generalization can be necessary.

1 - enrichment) In case of too vague data, it could be possible to enrich semantics using several techniques, such as ontology-based inferences and machine learning techniques (e.g. Dou et al., 2015; Lüscher et al., 2007; Xue et al., 2021; Bloch, Sacks, 2018; Werbrouck et al., 2020). Attention should be paid for the vagueness value not to be affected by this processing.

2 - generalization) Whether more generalised entities are necessary, superclasses can be used (either from the classification used by the data or mapping the data to other classifications, for example adopting a different perspective). The same techniques for data enrichment could be used, with the different objective of detecting superclasses, in case of differences in the semantic paradigm.

Semantic paradigm. As for geometry, a conversion can harmonize the paradigm.

3 - conversion) The criteria used in defining the conceptualization and filling the attributes have consequences on the resulting meaning of the entities and attribute values and need to be made homogeneous. Whether they are filled with a completely different perspective, objects and attributes must be recalculated or adapted. A transformation, defined through a mapping to a different conceptualization, must be applied, i.e., changing the semantics slightly (possibly also changing the representation) to make it suitable for purposes other than the original one (Klein, 2001). Such a distortion needs to be documented and tracked (Kavouras, Kokla, 2007). Moreover, the units of measurements for attributes' values must be converted to comply to the data requirements prescriptions.

Language. A language translation (3 - conversion) must be applied according to the need of application as reported by data requirements. Multilingual thesauri can be used whether available (Doerr, 2001). The buildingSMART Data Dictionary ${ }^{13}$ is an example.

Encoding. A conversion (3) is necessary in this case as well.

${ }^{13}$ http://bsdd.buildingsmart.org [Accessed 30 ${ }^{\text {th }}$ November, 2021] 


\subsubsection{Harmonization of the structure}

Granularity. Enrichment must be applied in case more detail is needed in the conceptualization, or generalization, in case higher level concepts are necessary.

1 - enrichment) After the mapping, inferences techniques should be applied to specify the objects to a finer granularity (e.g., some 'constructions' will become 'buildings').

2 - generalization) After the mapping, generalization techniques can be applied to generalise the object's conceptualizations, for example, by using superclasses in the reference classification (e.g. 'buildings' and 'infrastructures' will become 'constructions').

Semantic paradigm. After the mapping, the representation must be expressed according to the semantic paradigm defined in data requirements ( 3 - conversion).

Relationships. They can be enriched, generalized or simply converted.

1 - enrichment) Relationships between objects can be inferred through the previously mentioned inference techniques, whether the needed information is stored within the dataset.

2 - generalization) The mapping can support the generalization of relationships, guided by the destination conceptualization.

3 -conversion) The mapping must regard also the relationships between entities and the input dataset must be converted accordingly.

\subsubsection{Harmonization of the syntax}

Data format. Encoding language and the representation formalism, including version, must be considered.

3 - conversion) ETL tools, which can also be embedded into GIS tools or other models' exporters, can generally apply the conversion to the desired data formats (Noardo et al., 2020). In ontology engineering field it is called 'translation': changing the representation formalism of an ontology while preserving the semantics (Klein, 2001; KK, 2007).

Objects' behaviour. The mapping will be the reference tool to guide this processing as well in the three cases of enrichment (1), generalization (2) and/or conversion (3).

\subsection{Final data fusion and validation}

Although in some studies the term 'data fusion' is used to indicate the overall integration, here it is intended to represent specifically the merging of geometrical data overlapping on the same extent or bordering, by resolving the remaining conflicts after the harmonization, which are due to differences in the objects represented by both the sources. For example, discrepancies in DTM heights on certain area, or in the shape or presence of buildings, and so on.

First, priorities should be decided to choose the most reliable data to be maintained in the integrated data after data fusion. Such priorities should be (1) time 
(most recent source should be trusted in case of discrepancies); (2) quality (most accurate, less vague source should be preferred, as well as the closest source to data requirements prescriptions); (3) interest (the source representing the objects of interest, whether these are not present in both).

Data fusion is a common process for remote sensing applications, and is usually performed by spatial statistics applications (Nguyen et al., 2012; Zhang, 2010; Ghamisi et al., 2019). Other data fusion examples exist for 2D maps, mainly for update goals (Duckham, Worboys, 2005; Chen et al., 2013; Devogele, 2002) or for harmonising cross-border maps (Ledoux, Arroyo Ohori, 2017; Noardo et al., 2016). Furthermore, more recent studies take into account more complex information and multi-sensor 3D data (Wallgrün, Dylla, 2010; Dong et al., 2018; Ramos, Remondino, 2015; Zhu, Donia, 2013; Ahn et al., 2020).

More complex processing including the editing of 3D geometries or addition of 3D details should foresee the mapping of features or objects, possible (parametric) modelling phases or other kinds of merging, depending on the manipulated objects and kind of representation. Further studies, not performed so far, will be necessary to investigate the issue in more detail. For example, this could be useful to add specific building details to an already well-formed 3D city model.

The methodology to perform the final merging can be chosen among the different options, based on the kind of data considered and the remaining discrepancies. In the final integrated data set the two origin datasets must be no more recognizable, as much as possible, therefore holes and discrepancies in heights must be smoothed (Lingua, Noardo, 2016). A maximum tolerance in such discrepancy can be considered as the geometric accuracy established by the data requirements.

The integrated data obtained should be finally validated against the data requirements. In case such requirements were expressed in a formal, machine-readable, language, an automatic validator could be programmed. However, at present it would be hard to automate the full validation process. Even if, most likely, the single aspects of the data (e.g. geometry, structure and so on) can be validated separately, possibly with automatic validators ${ }^{14}$ whether they are quantitative or formalized.

\section{A case study to exemplify the proposed approach.}

A case study was chosen to exemplify and iteratively design the proposed approach in this paper. The goal of the integration is the update of a 3D city model (CityGML LoD0 and LoD1) (Figure 6) with the data coming from a BIM (IFC) representing the architectural model of a designed building, so called 'Terraced tower' (Figure 7), likely delivered for digital building permitting procedure. It is a rather simple case, to show how the proposed framework can be used for data integration in practice.

${ }^{14}$ E.g. http://geovalidation.bk.tudelft.nl [Accessed $1^{\text {st }}$ December 2021] 


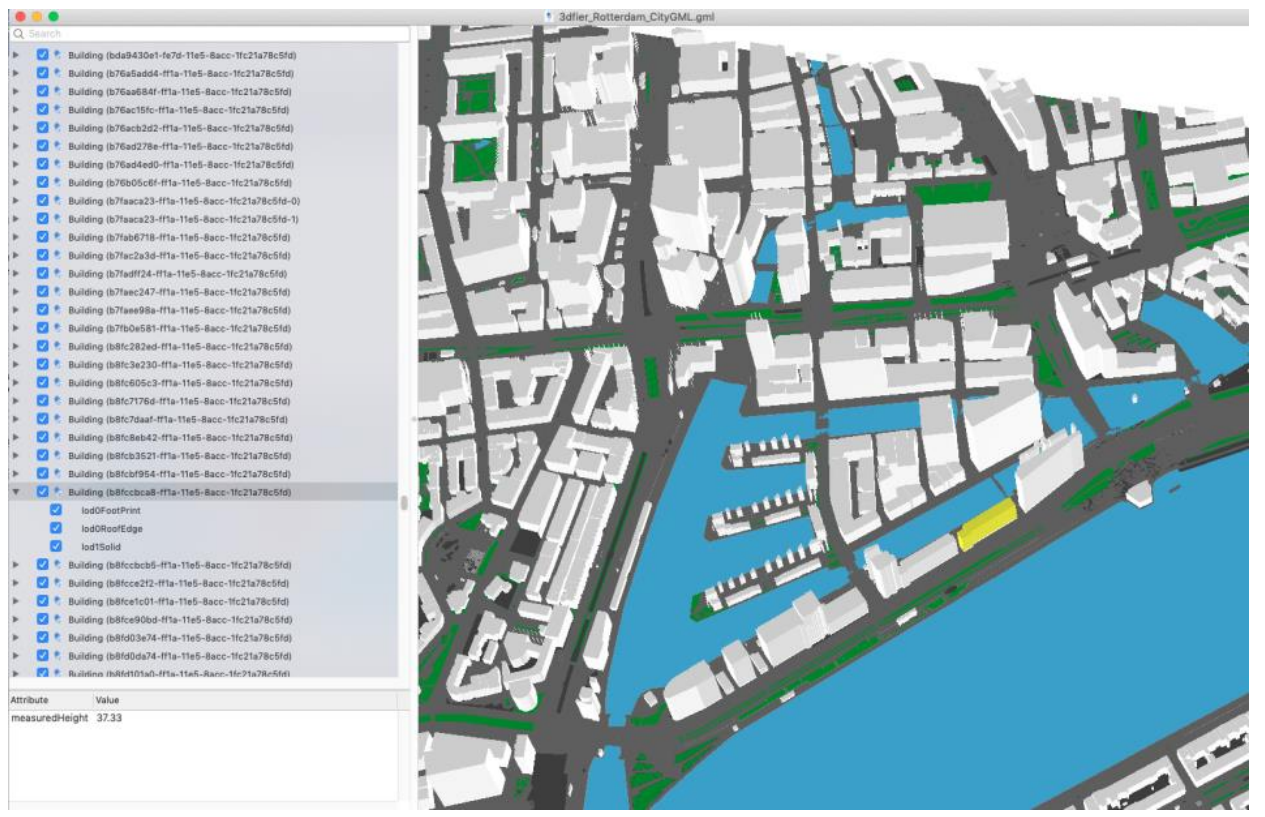

Figure 6. LoD1 CityGML model of Rotterdam visualized in azul. ${ }^{15}$ The building in yellow will be updated and substituted after the integration.

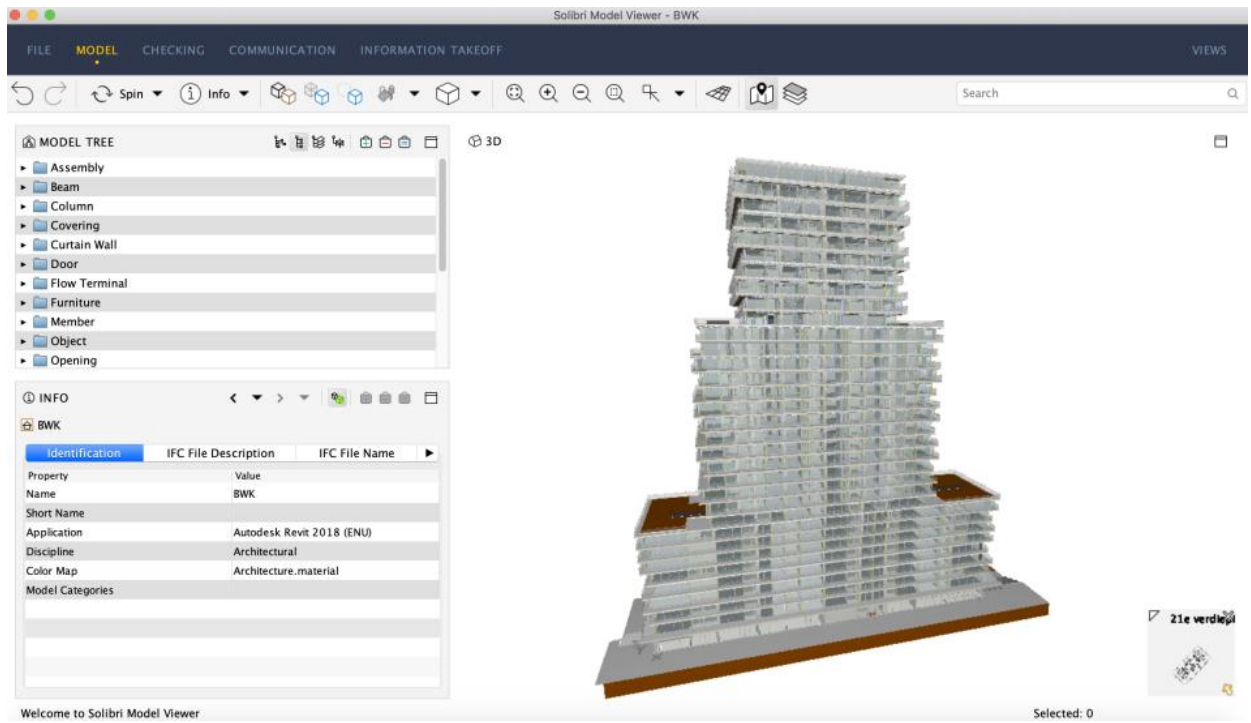

Figure 7. Architectural IFC model of the Terraced tower building, visualized in the

Solibri Model Viewer (https://www.solibri.com/solibri-anywhere [Accessed 2nd

December 2021]).

\subsection{Data requirements definition and integrability assessment}

The data requirements, in this case, correspond with the characteristics of the destination model, i.e., the LoD1 CityGML model of Rotterdam. In Tables A1-A5, in Annex 1, each parameter is analysed for the destination model (data requirement) and in the input model, i.e., the IFC model of the Terrace tower building. In the last column,

${ }^{15}$ https://github.com/tudelft3d/azul [Accessed 2nd December 2021]. 
the integrability (and, consequently, needed harmonization processing) is assessed and commented according to the framework proposed in Section 3.5.

\subsection{Processing of the IFC model towards harmonization}

As pointed out by the specific assessment (Table A1), the geometry needs to be generalized, converted into meters from millimeters and stored into a different format.

For doing this, the IFC geometry was processed to extract the footprint of the building and the maximum height. The GEOBIM_Tool ${ }^{16}$, developed for a project on the digitalization of the building permitting procedure in Rotterdam ${ }^{17}$ (Noardo et al., 2022), was used to extract the footprint from the IFC model and to measure the building maximum height. The tool automatically scales the model into metre unit of measure.

The footprint was used to generate: the footprint polygon (lod0FootPrint) at the ground level; the roof edge polygon (lod0RoofEdge), generated by storing the same polygon at the height of the maximum height measured from the IFC model; an extruded solid representing the 3D building (lod1Solid).

The extrusion can be generated from the footprint and maximum height of the building, using a similar approach as the one used for modelling the 3Dfier Rotterdam model. Finally, the geometries can be exported to GML.

Due to the chosen approach for the processing, the semantics can be useful to select the objects that need to be considered in the processing. The objects which are not part of the ifcBuilding, such as the parts of the model belonging to the site, outside the building, need to be excluded from the geometric processing. The conversion necessary, in this case, must consider the entire representation paradigm (both geometrical and semantic/structural): we need to be aware that in the IFC model, ifcBuilding is a class that groups other building elements represented with their own geometry, while in the CityGML model, it stores one only object with its own geometry(es).

In the storage of attributes and attribute values, there is no need for conversion, since, as resulted from the mapping, there is no attribute in IFC to store the maximum height of the building. However, the parameter measured from the IFC geometries can be stored in the correct place to match the destination data encoding and syntax.

\subsection{Final steps: data fusion, validation and metadata update.}

The data need to be merged into each other. Assessing and resolving the conflicts is quite simple in this case. The data coming from the processing of the IFC model will substitute the building in place in the outdated 3D city model, to generate an up-to-date version of it. The bordering objects (e.g. roads, land cover) need to be modified to obtain a watertight model (Figure 8).

Versioning techniques need to be considered for keeping track of the integration as a change in the data.

\footnotetext{
${ }^{16}$ https://github.com/twut/GEOBIM_Tool [Accessed 2nd December 2021]

${ }^{17}$ https://3d.bk.tudelft.nl/projects/rotterdamgeobim_bp/ [Accessed $2^{\text {nd }}$ December 2021]
} 


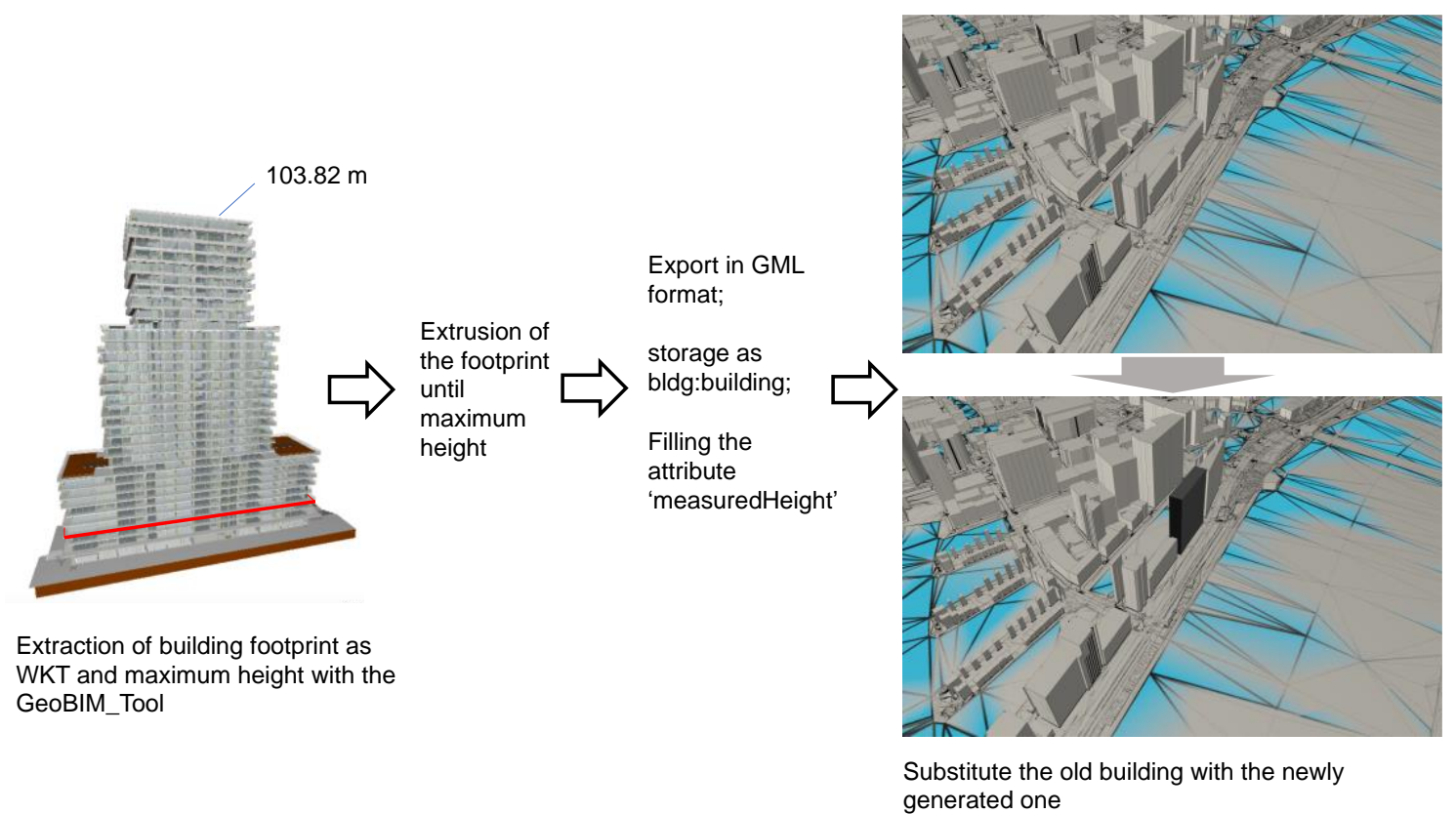

Figure 8. Processing followed for the integration (harmonization + data merging) as planned according to the initial assessment.

Similar approach could be used also in more simple cases, for example, to update 2D digital maps (e.g. Figure 9)

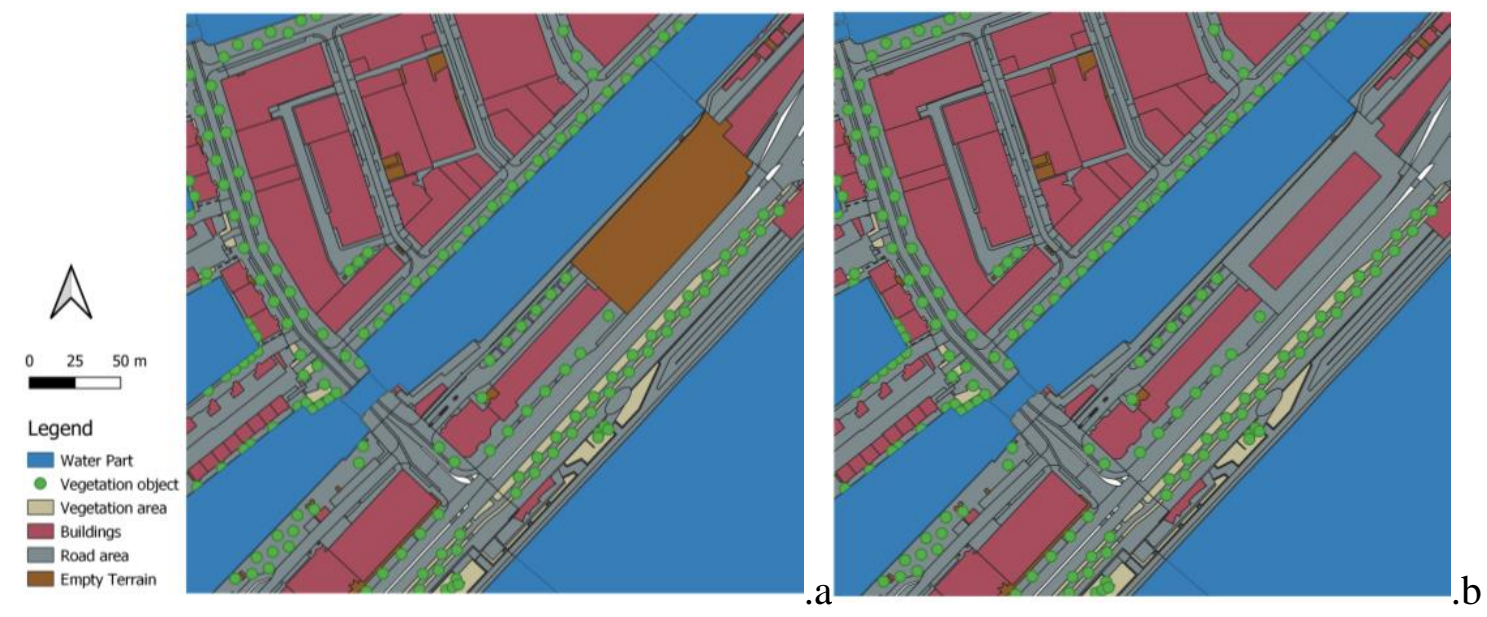

Figure 9. Example of the use of extracted data to update a 2D digital map (a. before; $b$. after the update), following the same workflow.

\section{Discussion}

The proposed methodology supports a point-by-point analysis to obtain an actual integration of datasets with respect to use case data requirements. The proposed framework joins the efforts made within different fields, such as ontology engineering, 3D survey and 3D city modelling.

Due to the high complexity of the issue, it was not possible to provide one only solution, but some options are suggested for each case. Who processes the integration 
will need to investigate the needed and available processes into detail by themselves, since the range of existing data are too heterogeneous and the use case requirements may be very specific for each case, which makes any suggestion for specific processing not effective. However, the proposed framework can be used for any kind of integration, representing a solid reference for future work.

\subsection{The automation of the methodology}

The integration framework, as defined in this paper, is very complex, including qualitative assessments in some cases. Therefore, it is hard to propose a fully automatic procedure to integrate datasets. At this moment the main aim of this approach is to have a transparent and clear methodology for effective data integration that can be reused in the future and at the same time highlight possible required improvements of individual data sources.

An automated workflow should be composed by many components and the level of possible automation would increase according to metadata's quality (they should be correct and specific), completeness (all the parameters should be well documented and explained) and formality of the storage language (they should be machine-readable). This would allow an algorithm to choose or suggest harmonization processing for each parameter and final data merging. However, at the moment, considering the available data (and metadata) from practice, automatic procedures can only be chosen to support the pre-processing harmonization steps for the single parameters. Moreover, some automatic or computer-assisted procedure can be used to extract the needed parameters from the data, whether these are not properly documented (e.g. Kavouras and Kokla, 2002). A manual or semi-manual guided analysis is still the preferable choice.

\subsection{An overall workflow}

The group of actions needed to convert the data into the integrated dataset can be implemented in different workflows. The kind of implementation and tools have to be chosen case by case, according to the complexity of the conversion, the level of possible automation and the need for repeating the process several times. They range from manual workflows, in which the actions intended to solve each of the detected inhomogeneities are launched manually step by step, to completely automated workflows, implemented in ETL tools, such as the popular Safe Software FME ${ }^{18}$, in software like GIS processing models, or in other bespoke implementations.

Currently, many studies developing converters of data, for example between BIM and GIS already consider several of the listed aspects together, most frequently the data format and data schema/semantics are taken into account (Stouffs et al., 2018; Salheb et al., 2020; Clemen et al., 2021; Barbato et al., 2018) and in the most advanced cases also the transformation of geometries according to the required representation paradigm (Donkers et al., 2016; Olsson et al., 2019).

Few examples are available about the complete workflow from data assessment to pre-processing and harmonization and final data merging into real integration.

${ }^{18}$ https://www.safe.com [Accessed $3^{\text {rd }}$ December 2021] 


\subsection{Discussion about metadata}

In order to allow a fast assessment, suitable metadata should contain up-to-date and specific information about all the mentioned points. However, many of them are not foreseen in the current standard metadata schemas.

Table 7 maps the metadata of some of the most popular Open standard data model to the parameters defined in Section 3.1. ISO $19115^{19}$ is the reference standard about metadata for geographic information. Most of other data models are compliant to it (INSPIRE, CityJSON), but they can present some variations if they include additional attributes or exclude some of the ISO attributes from the profile they use.

LandInfra standard ${ }^{20}$ is ISO19115 compliant as well (Kumar et al., 2019).

CityGML is not included in Table 7 because it has limited metadata support (i.e., only name of the dataset, bounding box, coordinate system), mostly optional and inherited from the GML encoding format. In some cases, more information is added in form of comments in the XML file, but there is no control and no shared prescription about what information must be provided and in what format (Labetski et al., 2018). Metadata support was not included in the version 3 of CityGML either.

Similarly, many IFC files can contain some additional metadata information in a commented section in the STEP file in which they are encoded (e.g., author, schema, creation date).

The HEADER of the STEP files can also host some additional information (e.g., description, time_stamp, author, originating_system, FILE_SCHEMA). However, they do not follow a specific prescription and are related to the generation of the STEP file, according to the specific implementation choices of software exporting it.

Table 7 - Mapping of the defined parameters to Open standards' metadata schemas. In green cells fully compliant information with the parameters considered in this paper can be found. In orange cells, some related information to the parameters is foreseen, or the link to unstructured documents within which more attributes can be searched.

\begin{tabular}{|c|c|c|c|c|c|}
\hline & & IS019115 & INSPIRE $^{21}$ & IFC & CityJSON \\
\hline \multirow{5}{*}{ 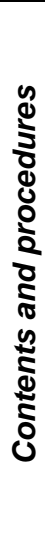 } & Spatial extent & $\begin{array}{l}\text { Geographic } \\
\text { location of the } \\
\text { dataset }\end{array}$ & $\begin{array}{l}\text { geographic } \\
\text { bounding box }\end{array}$ & & $\begin{array}{l}\text { geographicalExte } \\
\text { nt }\end{array}$ \\
\hline & Temporal frame & $\begin{array}{l}\text { Dataset reference } \\
\text { date, Additional } \\
\text { extent information } \\
\text { for the dataset }\end{array}$ & $\begin{array}{l}\text { temporal } \\
\text { reference, } \\
\text { temporal extent, } \\
\text { date of last } \\
\text { revision, date of } \\
\text { creation } \\
\end{array}$ & & $\begin{array}{l}\text { datasetReference } \\
\text { Date }\end{array}$ \\
\hline & Scope & $\begin{array}{l}\text { Dataset topic } \\
\text { category }\end{array}$ & $\begin{array}{l}\text { resource type, } \\
\text { topic category }\end{array}$ & IDM, IDS & $\begin{array}{l}\text { datasetTopicCate } \\
\text { gory }\end{array}$ \\
\hline & $\begin{array}{l}\text { Goal and use case } \\
\text { requirements }\end{array}$ & $\begin{array}{l}\text { Abstract } \\
\text { describing the } \\
\text { dataset }\end{array}$ & $\begin{array}{l}\text { Resource } \\
\text { abstract }\end{array}$ & IDM, IDS & $\begin{array}{l}\text { Abstract, } \\
\text { specificUsage }\end{array}$ \\
\hline & Lineage & Lineage & Lineage & & lineage \\
\hline
\end{tabular}

\footnotetext{
${ }^{19}$ https://www.iso.org/standard/53798.html [Accessed 24th November 2021]

${ }^{20}$ https://www.ogc.org/standards/landinfra [Accessed 24th November 2021]

21 The INSPIRE metadata model is based on ISO19115, ISO19119 and ISO 15836 (Dublin
}

Core) (ECJRC, 2010) 


\begin{tabular}{|c|c|c|c|c|c|}
\hline & Author & $\begin{array}{l}\text { Dataset } \\
\text { responsible party }\end{array}$ & $\begin{array}{l}\text { Responsible } \\
\text { organization }\end{array}$ & & \\
\hline & $\begin{array}{l}\text { Implementation } \\
\text { requirements }\end{array}$ & & specifications $^{22}$ & & $\begin{array}{l}\text { spatialRepresent } \\
\text { ationType }\end{array}$ \\
\hline \multirow{6}{*}{ ڤ్ } & Accuracy & & specifications & & \\
\hline & Abstraction level & $\begin{array}{l}\text { Spatial resolution } \\
\text { of the dataset }\end{array}$ & Spatial resolution & & presentLoDs \\
\hline & Geometry paradigm & $\begin{array}{l}\text { Spatial } \\
\text { representation } \\
\text { type }\end{array}$ & specifications & IDM, IDS, MVD & \\
\hline & Topology & & specifications & IDM, IDS, MVD & \\
\hline & Georeferencing & $\begin{array}{l}\text { Reference } \\
\text { system }\end{array}$ & specifications & $\begin{array}{l}\text { IfcMapConversio } \\
n\end{array}$ & referenceSystem \\
\hline & Unit of measure & & specifications & $\begin{array}{l}\text { IfcProject - } \\
\text { ProjectUnits }\end{array}$ & \\
\hline \multirow{9}{*}{ 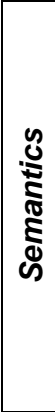 } & Entities & & specifications & IDM, IDS, MVD & \\
\hline & $\begin{array}{l}\text { Properties and } \\
\text { attributes }\end{array}$ & & specifications & IDM, IDS, MVD & \\
\hline & Codelists and values & & specifications & IDM, IDS, MVD & \\
\hline & Terms & & specifications & IDM, IDS, MVD & \\
\hline & Accuracy (vagueness) & & specifications & & \\
\hline & Approximation level & & specifications & & \\
\hline & Semantic paradigm & & specifications & IDM, IDS, MVD & \\
\hline & Language & Dataset language & $\begin{array}{l}\text { resource } \\
\text { language }\end{array}$ & & datasetLanguage \\
\hline & Encoding & & specifications & & \\
\hline \multirow{8}{*}{ के } & Is-a hierarchies; & & specifications & IDM, IDS, MVD & \\
\hline & $\begin{array}{l}\text { Part-of meronymic } \\
\text { hierarchies; }\end{array}$ & & specifications & IDM, IDS, MVD & \\
\hline & Relationships & & specifications & IDM, IDS, MVD & \\
\hline & Reference data model, & & specifications & IDM, IDS, MVD & \\
\hline & version & & specifications & IDM, IDS, MVD & \\
\hline & profile & & specifications & IDM, IDS, MVD & \\
\hline & extensions & & specifications & IDM, IDS, MVD & \\
\hline & Granularity & & specifications & IDM, IDS, MVD & \\
\hline \multirow{2}{*}{$\omega$} & Data format & & specifications & IDM, IDS, MVD & \\
\hline & Objects' behavior & & specifications & IDM, IDS, MVD & \\
\hline
\end{tabular}

In Table 7, only the metadata regarding the technical details of the data are considered, while others, related to non-technical aspects (licencing, use and retrieval of data, publication details) are not reported.

As already pointed out by Labetski et al. (2018), many attributes about the datasets, which could be relevant for their correct interpretation and (re)use, as well as for their integration, are currently missing in the official metadata schemas. They link to external specifications document, in some cases (e.g. INSPIRE) but without guaranteeing or prescribing anything about the information there contained.

In the table we can notice how only a minimal part of the useful attributes is covered by metadata schemas. Both INSPIRE and IFC foresee the use of external documents to specify further information. The buildingSMART standards related to IFC propose a formal way to encode such information, while no guidelines are prescribed by the INSPIRE data model. However, there is currently little specification about what information should be stored in the documents or files and how, since many buildingSMART standards are still in the process of being defined. In addition, there are

\footnotetext{
${ }^{22}$ Reference to an external document where all detailed specifications can be described.
}

However, there is no guideline about what to include in such specifications. 
few examples of the use of such tools in practice. The use of metadata in general, in practice, is often still neglected.

\section{Conclusions}

To provide a reference for spatial data integration to support use cases applications (e.g. GeoBIM, digital twins, governance digitalization, land analysis), a methodology is provided considering all the aspects involved: geometry, semantics, structure and syntax.

By following the provided methodology, one can avoid neglecting some part of the data characteristics and plan a proper and consistent harmonization and merging processing.

Future work will be directed at testing in more detail each variable detected in the assessment matrixes and testing the methodology with more cases and more complex data.

\section{Data availability statement (DAS)}

The data about the case study example that support the findings of this study are openly available in Zenodo at http://doi.org/10.5281/zenodo.5786656, except for the original IFC model, which I do not have the rights to share publicly.

\section{References}

Ahn, D., Claridades, A.R.C., and Lee, J., 2020. Integrating Image and Network-Based Topological Data through Spatial Data Fusion for Indoor Location-Based Services, Journal of Sensors, 2020. DOI:10.1155/2020/8877739

Arroyo Ohori K, Diakité A, Krijnen T, Ledoux H, and Stoter J., 2018. Processing BIM and GIS Models in Practice: Experiences and Recommendations from a GeoBIM Project in The Netherlands. ISPRS International Journal of GeoInformation. 7(8):311. DOI:10.3390/ijgi7080311

Arroyo Ohori, K., 2020. azul: A fast and efficient 3D city model viewer for macOS. Transactions in GIS, 24(5), 1165-1184. DOI: 10.1111/tgis.12673

Baig, S.U. and Abdul-Rahman, A., 2013a. Generalization of buildings within the framework of CityGML, Geo-spatial Information Science, 16(4), 247-255, DOI:10.1080/10095020.2013.866617

Baig, S. U., and Abdul-Rahman, A., 2013b. Generalization and visualization of 3D building models in CityGML. In:Progress and New Trends in 3D Geoinformation Sciences. 63-77. Springer, Berlin, Heidelberg. Barbato, D., Pristeri, G., and De Marchi, M., 2018. GIS-BIM Interoperability for Regeneration of Transurban Areas. In: REAL CORP 2018-EXPANDING 
CITIES-DIMINISHING SPACE. Are "Smart Cities" the solution or part of the problem of continuous urbanisation around the globe? Proceedings of $23 \mathrm{rd}$ International Conference on Urban Planning, Regional Development and Information. 243-250. CORP-Compentence Center of Urban and Regional Planning.

Biljecki, F., Heuvelink, G. B. M., Ledoux, H., and Stoter, J., 2015. Propagation of positional error in 3D GIS: Estimation of the solar irradiation of building roofs. International Journal of Geographical Information Sciences, 29(12), 22692294. DOI:10.1080/ 13658816.2015.1073292

Biljecki, F., Ledoux, H., and Stoter, J., 2016. An improved LOD specification for 3D building models. Computers, Environment, and Urban Systems, 59, 25-37.

Biljecki, F., and Dehbi, Y., 2019. Raise the roof: towards generating LoD2 models without aerial surveys using machine learning. ISPRS Annals of Photogrammetry, Remote Sensing and Spatial Information Sciences, 4.

Biljecki, F., and Tauscher, H., 2019. Quality of BIM-GIS conversion. ISPRS Annals of Photogrammetry, Remote Sensing and Spatial Information Sciences, 4.

Bloch, T., and Sacks, R., 2018. Comparing machine learning and rule-based inferencing for semantic enrichment of BIM models. Automation in Construction, 91, 256272. DOI:10.1016/j.autcon.2018.03.018

Chen, H., Sun, Q., Xu, L., and Xiong, Z., 2013. Application of data fusion in the production and updating of spatial data. ISPRS-International Archives of the Photogrammetry, Remote Sensing and Spatial Information Sciences, 7, W1.

Clemen, C. and Görne, H., 2019. Level of Georeferencing (LoGeoRef) using IFC for BIM. Journal of Geodesy, Cartography and Cadastre. 10, 15-20.

Clemen, C., Kaiser, T., Romanschek, E., and Schröder, M., 2021. Site Plan for BIM?-A Free and Open Source Plug-In for As-Is Vicinity Models to be Used in Small and Medium-Sized BIM-Projects. In:FIG e-Working Week 2021 Smart Surveyors for Land and Water Management - Challenges in a New Reality Virtual, 21-25 June 2021.

Cockcroft, S., 1997. A Taxonomy of Spatial Data Integrity Constraints. GeoInformatica 1, 327-343. DOI:10.1023/A:1009754327059

Colucci, E., Kokla, M., and Norado, F., 2020. Semantic Comparison of 3D City Datasets and Mapping to Geospatial Ontologies. Conference presentation, in 3DGeonfo Conference 2020, Virtual Event, September 2020. 
Dabove, P., and Di Pietra, V., 2019. Single-Baseline RTK Positioning Using DualFrequency GNSS Receivers Inside Smartphones. Sensors. 19(19):4302. DOI: $10.3390 / \mathrm{s} 19194302$

Dextre Clarke, S., 2011. ISO 25964: a standard in support of KOS interoperability. In Facets of knowledge organization: proceedings of the ISKO UK Second Biennial Conference, 4th-5th July 2011, London. 129-134.

Dextre Clarke, S. G., and Zeng, M. L., 2012. From ISO 2788 to ISO 25964: The evolution of thesaurus standards towards interoperability and data modelling. Information Standards Quarterly (ISQ), 24(1).

Devogele, T., Parent, C., and Spaccapietra, S., 1998. On spatial database integration. International Journal of Geographical Information Science, 12(4), 335-352. DOI: $\underline{10.1080 / 136588198241824}$

Devogele, T., 2002. A new merging process for data integration based on the discrete Fréchet distance. Advances in spatial data handling. Springer, Berlin, Heidelberg. 167-181.

Diakité, A.A., Damiand, G., van Maercke, D., 2014. Topological Reconstruction of Complex 3D Buildings and Automatic Extraction of Levels of Detail. In: Eurographics Workshop on Urban Data Modelling and Visualisation, Strasbourg, France. 25-30, DOI:10.2312/udmv.20141074.

Doan, A., Madhavan, J., Domingos, P., and Halevy, A., 2004. Ontology matching: A machine learning approach. In: Handbook on ontologies. Springer, Berlin, Heidelberg. 385-403.

Doerr, M., 2001. Semantic problems of thesaurus mapping. Journal of Digital information, 1(8), 2001-03.

Doerr, M., 2004. Semantic interoperability: theoretical considerations. TR 345, Institute of Computer Science, FORTH, Science and technology Park of Crete, Crete, Greece.

Dong, W., Wang, Q., Wang, X., and Zha, H., 2018. PSDF fusion: Probabilistic signed distance function for on-the-fly $3 \mathrm{D}$ data fusion and scene reconstruction. In: Proceedings of the European Conference on Computer Vision (ECCV) 701-717.

Donkers, S., Ledoux, H., Zhao, J., and Stoter, J., 2016. Automatic conversion of IFC datasets to geometrically and semantically correct CityGML LOD3 buildings. Transactions in GIS, 20(4), 547-569. 
Dou, D., Wang, H., and Liu, H., 2015. Semantic data mining: A survey of ontologybased approaches. In: Proceedings of the 2015 IEEE 9th International Conference on Semantic Computing (IEEE ICSC 2015), 2015, 244-251, DOI: 10.1109/ICOSC.2015.7050814.

Duchêne, C., Baella, B., Brewer, C. A., Burghardt, D., Buttenfield, B. P., Gaffuri, J., Käuferle, D., Lecordix, F., Maugeais, E., Nijhuis, R., Pla, M., Post M., Regnauld, N., Stanislawski, L. V., Stoter, J., Tóth, K., Urbanke, S., van Altena, V., and Wiedemann, A., 2014. Generalisation in practice within national mapping agencies. In Abstracting geographic information in a data rich world. 329-391. Springer, Cham.

Duckham, M., and Worboys, M., 2005. An algebraic approach to automated geospatial information fusion. International Journal of Geographical Information Science, 19(5), 537-557. DOI: $10.1080 / 13658810500032339$

ECJRC - Drafting Team Metadata and European Commission Joint Research Centre, 2010. INSPIRE Metadata Implementing Rules: Technical Guidelines based on EN ISO 19115 and EN ISO 19119. INSPIRE MD_IR_and_ISO_v1_2_20100616

Egenhofer, M. J., and Frank, A., 1992. Object-oriented modeling for GIS. Journal of the Urban and Regional Information Systems Association, 4(2), 3-19.

Egenhofer, M.J., Clementini, E., and di Felice, P., 1994. Research Paper, International Journal of Geographical Information Science, 8:2, 129-142, DOI: $10.1080 / 02693799408901990$

Ellul, C., Noardo, F., Harrie, L., and Stoter, J., 2020. the EuroSDR GeoBIM project developing case studies for the use of GeoBIM in practice, Int. Arch. Photogramm. Remote Sens. Spatial Inf. Sci., XLIV-4/W1-2020, 33-40, DOI:10.5194/isprs-archives-XLIV-4-W1-2020-33-2020.

Gaffuri, J., 2011. Improving web mapping with generalization. Cartographica: The International Journal for Geographic Information and Geovisualization, 46(2), 83-91.

Geiger, A., Benner, J., and Haefele, K. H., 2015. Generalization of 3D IFC building models. In: 3D geoinformation science. 19-35. Springer, Cham.

Ghamisi, P., Rasti, B., Yokoya, N., Wang, Q., Hofle, B., Bruzzone, L., Bovolo, F., Chi, M., Anders, K., Gloaguen, R., Atkinson, P.M., and Benediktsson, J.A., 2019. Multisource and Multitemporal Data Fusion in Remote Sensing: A 
Comprehensive Review of the State of the Art. IEEE Geoscience and Remote Sensing Magazine, 7(1), 6-39. DOI: 10.1109/MGRS.2018.2890023.

Girres, J. F., and Touya, G., 2010. Quality assessment of the French OpenStreetMap dataset. Transactions in GIS, 14(4), 435-459. DOI: 10.1111/j.14679671.2010.01203.X

Gröger, G., and Plümer, L., 2012. CityGML-Interoperable semantic 3D city models. ISPRS Journal of Photogrammetry and Remote Sensing, 71, 12-33.

Guercke, R., and Brenner, C., 200. A Framework for the Generalization of 3D City Models. In: Proceedings of 12th AGILE Conference on GIScience, 31.

Haklay, M., 2010. How good is volunteered geographical information? A comparative study of OpenStreetMap and Ordnance Survey datasets. Environment and planning B: Planning and design, 37(4), 682-703.

Hiebel, G., Doerr, M. and Eide, Ø., 2017. CRMgeo: A spatiotemporal extension of CIDOC-CRM. Int J Digit Libr 18, 271-279. DOI:10.1007/s00799-016-0192-4

Jaud, Š., Donaubauer, A., Heunecke, O., and Borrmann, A., 2020 Georeferencing in the context of building information modelling. Autom. Constr. 118, 103211.

Jun, X., 2019. An Improved Spatial Topological Relationship Model and Algorithm. In 2019 3rd International Conference on Electronic Information Technology and Computer Engineering (EITCE) IEEE. 993-997.

Kavouras, M., and Kokla, M., 2002. A method for the formalization and integration of geographical categorizations. International Journal of Geographical Information Science, 16(5), 439-453.

Kavouras, M., and Kokla, M., 2007. Theories of geographic concepts: ontological approaches to semantic integration. CRC Press. ISBN: 978-0-8493-3089-6

Klein, M., 2001. Combining and relating ontologies: an analysis of problems and solutions. In: Proc. IJCAI-01 Workshop: Ontologies and Information Sharing, Seattle, WA.

Krijnen, T., Noardo, F., Ohori, K. A., Ledoux, H., and Stoter, J., 2020. Validation and Inference of Geometrical Relationships in IFC. In Proceedings of the 37th International Conference of CIB W. 78.

Kumar, K., Labetski, A., Ohori, K., Ledoux, H., and Stoter, J., 2019. The LandInfra standard and its role in solving the BIM-GIS quagmire. Open geospatial data, softw. stand. 4(5). DOI:10.1186/s40965-019-0065-z 
Labetski, A., Kumar, K., Ledoux, H., and Stoter, J., 2018. A metadata ADE for CityGML. Open geospatial data, softw. stand. 3(16). DOI:10.1186/s40965-0180057-4

Latiffi, A. A., Brahim, J., Mohd, S., and Fathi, M. S., 2015. Building information modeling (BIM): exploring level of development (LOD) in construction projects. In Applied Mechanics and Materials. 773. Trans Tech Publications Ltd. 933-937.

Laurini, R., and Thompson, D., 1992. Fundamentals of spatial information systems. Academic press. 37. ISBN: 0-12-438380-7

Laurini, R., 1998. Spatial multi-database topological continuity and indexing: a step towards seamless GIS data interoperability. International Journal of Geographical Information Science, 12(4), 373-402, DOI:10.1080/136588198241842

Ledoux, H., Arroyo Ohori, K., 2017. Solving the horizontal conflation problem with a constrained Delaunay triangulation. J Geogr Syst 19, 21-42.

DOI:10.1007/s10109-016-0237-7

Ledoux, H., 2018. val3dity: validation of 3D GIS primitives according to the international standards. Open geospatial data, softw. stand. 3(1). DOI:10.1186/s40965-018-0043-X

Ledoux, H., Arroyo Ohori, K., Kumar, K., Dukai, B., Labetski, A., and Vitalis, S., 2019. CityJSON: A compact and easy-to-use encoding of the CityGML data model. Open Geospatial Data, Software and Standards, 4(1), 1-12.

Ledoux, H., Biljecki, F., Dukai, B., Kumar, K., Peters, R., Stoter, J., and Commandeur, T., 2021. 3dfier: automatic reconstruction of 3D city models. Journal of Open Source Software, 6(57), 2866.

Ledoux, H., Biljecki, F., Dukai, B., Kumar, K., Peters, R., Stoter, J., and Commandeur, T., 2021. 3dfier: automatic reconstruction of 3D city models. Journal of Open Source Software, 6(57), 2866.

Lenzerini, M., 2002. Data integration: A theoretical perspective. In Proceedings of the twenty-first ACM SIGMOD-SIGACT-SIGART symposium on Principles of database systems. 233-246. DOI:10.1145/543613.543644

Lingua, A. and Noardo, F., 2016. Geomatics as Effective Environmental Monitoring Support. In: European Space project on Smart Systems, Big Data, Future 
Internet - Towards Serving the Grand Societal Challenges - EPS Rome 2016, ISBN 978-989-758-207-3, 73-91. DOI: 10.5220/0007903000730091

Lunetta, R., Congalton, R., Fenstermaker, L., Jensen, J., Mcgwire, K., and Tinney, L. R., 1991. Remote sensing and geographic information system data integrationError sources and research issues. Photogrammetric engineering and remote sensing, 57(6), 677-687.

Lüscher, P., Burghardt, D., Weibel, R., 2007. Ontology-driven enrichment of spatial databases. In: 10th ICA Workshop on Generalisation and Multiple Representation, Moskau, 2 August 2007 - 3 August 2007. International Cartographic Association, online.

Malinowski, E., and Zimányi, E., 2006. Requirements specification and conceptual modeling for spatial data warehouses. In: OTM Confederated International Conferences" On the Move to Meaningful Internet Systems" Springer, Berlin, Heidelberg. 1616-1625.

McGuinness, D. L., Fikes, R., Rice, J., and Wilder, S., 2000. An environment for merging and testing large ontologies. In: Cohn, A.G., Giunchiglia, F., and Selman, B., editors, KR2000: Principles of Knowledge Representation and Reasoning, 483-493, San Francisco, 2000. Morgan Kaufmann.

Mohammadi, H. Binns, A. Rajabifard, A., and Williamson, I. P., 2006. Spatial Data Integration. In: Seventeenth UN Regional Cartographic Conference for Asia and the Pacific, Bangkok. http://hdl.handle.net/11343/26704 [Accessed $2^{\text {nd }}$ December 2021]

Mohammadi, H., Rajabifard, A., and Williamson, I.P., 2010. Development of an interoperable tool to facilitate spatial data integration in the context of SDI, International Journal of Geographical Information Science, 24(4), 487-505, DOI: $10.1080 / 13658810902881903$

Morocho, V., Saltor, F., and Pérez-Vidal, L., 2003. Schema Integration on Federated Spatial DB Across Ontologies. In Engineering Federated Information Systems, In: Proceedings of the 5th Workshop EFIS 2003 ISBN 1-58603-359-X. 63-72.

Mostafavi, M. A., 2006. Semantic similarity assessment in support of spatial data integration. In: 7th International Symposium on Spatial Accuracy Assessment in Natural Resources and Environmental Sciences. 
Nguyen, H., Cressie, N., and Braverman, A., 2012. Spatial Statistical Data Fusion for Remote Sensing Applications. Journal of the American Statistical Association, 107:499, 1004-1018, DOI: $\underline{10.1080 / 01621459.2012 .694717}$

Noardo, F., Lingua, A., Aicardi, I., and Vigna, B., 2016. Cartographic data harmonisation for a cross-border project development. Applied Geomatics, 8(3), 133-150. DOI:10.1007/s12518-016-0172-9

Noardo, F., Ellul, C., Harrie, L., Overland, I., Shariat, M., Arroyo Ohori, K., and Stoter, J., 2020a. Opportunities and challenges for GeoBIM in Europe: developing a building permits use-case to raise awareness and examine technical interoperability challenges. Journal of Spatial Science, 65(20, 209-233, DOI: $\underline{10.1080 / 14498596.2019 .1627253}$

Noardo, F., Harrie, L., Arroyo Ohori, K., Biljecki, F., Ellul, C., Krijnen, T., Eriksson, H., Guler, D., Hintz, D., Jadidi, M.A., Pla, M., Sanchez, S., Soini. V.-P., Stouffs, R., Tekavec, J., and Stoter, J., 2020b. Tools for BIM-GIS Integration (IFC Georeferencing and Conversions): Results from the GeoBIM Benchmark 2019. ISPRS International Journal of Geo-Information. 9(9):502.

DOI:10.3390/ijgi9090502

Noardo, F., Krijnen, T., Arroyo Ohori, K., Biljecki, F., Ellul, C., Harrie, L., Eriksson, H., Polia, L., Salheb, N., Tauscher, H., van Liempt, J., Goerne, H., Hintz, D., Kaiser, T., Leoni, C., Warchol, A., and Stoter, J., 2021a. Reference study of IFC software support: the GeoBIM benchmark 2019 - Part I. Transactions in GIS 25(2) 805-841. DOI:10.1111/tgis.12709

Noardo, F., Arroyo Ohori, K., Biljecki, F., Ellul, C., Harrie, L., Krijnen, T., Eriksson, H., van Liempt, J., Pla, M., Ruiz, A., Hintz, D., Krueger, N., Leoni, C., Leoz, L., Moraru, D., Vitalis, S., Willkomm, P., and Stoter, J., 2021b. Reference study of CityGML software support: the GeoBIM benchmark 2019 - Part II.Transactions in GIS 25(2), 842-868. DOI:10.1111/tgis.12710

Noardo F, Arroyo Ohori K, Krijnen T, and Stoter J. 2021c. An Inspection of IFC Models from Practice. Applied Sciences. 11(5):2232.

DOI:10.3390/app11052232

Noardo, F., Wu, T., Arroyo Ohori, K., Krijnen, T., and Stoter, J., 2022. IFC models for semi-automating common planning checks for building permit. Automation in Construction. 134, 104097. DOI: 10.1016/j.autcon.2021.104097 
Noskov, A., and Doytsher, Y., 2017. A Linear Approach to Improving the Accuracy of City Planning and OpenStreetMap Road Datasets. International Journal on Advances in Systems and Measurements, 10(1and2), 23-34.

DOI:10.5281/zenodo.1314636

OGC - Open Geospatial Consortium, 2012. OGC City Geography Markup Language (CityGML) Encoding Standard. OGC 12-019 Version 2.0.0. http://www.opengis.net/spec/citygml/2.0 [Accessed 2nd December 2021]

Olsson, P. O., Johansson, T., Eriksson, H., Lithen, T., Bengtsson, L. H., Axelsson, J., Roos, U., Neland, K., Rydén, B., Harrie, L., 2019. Unbroken digital data flow in the built environment process-a case study in Sweden. International Archives of the Photogrammetry, Remote Sensing and Spatial Information Sciences. XLII2/W13, 1347-1352. DOI:10.5194/isprs-archives-XLII-2-W13-1347-2019, 2019.

Osman, I., Yahia, S. B., and Diallo, G., 2021. Ontology integration: Approaches and challenging issues. Information Fusion, 71, 38-63.

DOI:10.1016/j.inffus.2021.01.007

Park, Y., and Guldmann, J. M., 2019. Creating 3D city models with building footprints and LIDAR point cloud classification: A machine learning approach.

Computers, environment and urban systems, 75, 76-89. Doi: 10.1016/j.compenvurbsys.2019.01.004

Ramos, M. M., and Remondino, F., 2015. Data fusion in cultural heritage-A review. The International Archives of Photogrammetry, Remote Sensing and Spatial Information Sciences, 40(5), 359.

Rodriguez, M. A., and Egenhofer, M. J., 2003. Determining semantic similarity among entity classes from different ontologies. In: IEEE Transactions on Knowledge and Data Engineering, 15(2), 442-456. DOI: 10.1109/TKDE.2003.1185844.

Perumal, M., Velumani, B., Sadhasivam, A., and Ramaswamy, K., 2015. Spatial Data Mining Approaches for GIS - A Brief Review. In: Satapathy S., Govardhan A., Raju K., Mandal J. (eds) Emerging ICT for Bridging the Future - Proceedings of the 49th Annual Convention of the Computer Society of India CSI Volume 2. Advances in Intelligent Systems and Computing, vol 338. Springer, Cham. DOI:10.1007/978-3-319-13731-5_63

Salheb, N., Arroyo Ohori, K., and Stoter, J., 2020. Automatic conversion of CityGML to IFC, Int. Arch. Photogramm. Remote Sens. Spatial Inf. Sci., XLIV-4/W12020, 127-134. DOI:10.5194/isprs-archives-XLIV-4-W1-2020-127-2020, 2020. 
Sheeren, D., Mustière, S., and Zucker, J. D., 2004. How to integrate heterogeneous spatial databases in a consistent way?. In East European Conference on Advances in Databases and Information Systems Springer, Berlin, Heidelberg. 364-378

Spyns, P., Meersman, R., and Jarrar, M., 2002. Data modelling versus ontology engineering. ACM SIGMod Record, 31(4), 12-17. DOI: $\underline{10.1145 / 637411.637413}$

Stoter, J., Post, M., van Altena, V., Nijhuis, R., and Bruns, B., 2014. Fully automated generalization of a 1: 50k map from 1: 10k data. Cartography and Geographic Information Science, 41(1), 1-13.

Stouffs, R., Tauscher, H., Biljecki, F., 2018. Achieving Complete and Near-Lossless Conversion from IFC to CityGML. ISPRS International Journal of GeoInformation. 7(9):355. DOI:10.3390/ijgi7090355

Sun, J., Olsson, P.O., Eriksson, H., and Harrie L., 2019. Evaluating the geometric aspects of integrating BIM data into city models, Journal of Spatial Science, DOI:10.1080/14498596.2019.1636722

Thapa, K., and Bossler, J., 1992. Accuracy of spatial data used information systems. Photogrammetric Engineering and Remote Sensing, 58(6), 835-841.

Worboys, M. F., and Duckham, M., 2004. GIS: a computing perspective. CRC press.

Uggla, G., Horemuz, M., 2018. Geographic capabilities and limitations of Industry Foundation Classes. Autom. Constr. 96, 554-566.

Uitermark, H.T., van Oosterom, P.J.M., Mars, N.J.I., Molenaar, M., 2005. Ontologybased integration of topographic data sets, International Journal of Applied Earth Observation and Geoinformation, 7(2), 97-106, ISSN 0303-2434, DOI:10.1016/j.jag.2005.03.002.

Ulubay, A., and Altan, M. O., 2002. A different approach to the spatial data integration. International Archives of Photogrammetry Remote Sensing And Spatial Information Sciences, 34(4), 656-661.

Van den Brink, L., Stoter, J., and Zlatanova, S., 2013a. Establishing a national standard for 3D topographic data compliant to CityGML, International Journal of Geographical Information Science, 27:1, 92-113, DOI: $\underline{10.1080 / 13658816.2012 .667105}$

Van den Brink, L., Stoter, J., and Zlatanova, S., 2013b. UML-based approach to developing a CityGML application domain extension. Transactions in GIS, 17(6), 920-942. DOI:10.1111/tgis.12026 
Van Heerden, N., 2021. BIM and 3D City Models as Input for Microclimate Simulation. MSc thesis in geomatics, Delft University of Technology. http://resolver.tudelft.nl/uuid:630d57be-5660-4971-84c2-83bf12b1d204 [Accessed $2^{\text {nd }}$ December 2021]

Vitalis, S., Arroyo Ohori, K., and Stoter, J., 2019. Incorporating topological representation in 3D city models. ISPRS International Journal of GeoInformation, 8(8), 347.

Wache, H., Voegele, T., Visser, U., Stuckenschmidt, H., Schuster, G., Neumann, H., and Hübner, S., 2001. Ontology-based integration of information-a survey of existing approaches. In Proc. IJCAI-01 Workshop: Ontologies and Information Sharing, Seattle, WA, ed. H. Stuckenschmidt. 108-117.

Wallgrün, J. O., and Dylla, F., 2010. A relation-based merging operator for qualitative spatial data integration and conflict resolution. Technical Report 022-06/2010, Transregional Collaborative Research Center SFB/TR 8 Spatial Cognition.

Wang, L., 2017. Heterogeneous data and big data analytics. Automatic Control and Information Sciences, 3(1), 8-15.

Werbrouck, J., Pauwels, P., Bonduel, M., Beetz, J., and Bekers, W., 2020. Scan-tograph: Semantic enrichment of existing building geometry. Automation in Construction, 119, 103286.

Wiemann, S., and Bernard, L., 2016 Spatial data fusion in Spatial Data Infrastructures using Linked Data. International Journal of Geographical Information Science, 30:4, 613-636, DOI: 10.1080/13658816.2015.1084420

Worboys, M. F., and Duckham, M., 2004. GIS: a computing perspective. CRC press. ISBN: 0-415-28375-2

Xue, F., Wu, L., and Lu, W., 2021. Semantic enrichment of building and city information models: A ten-year review. Advanced Engineering Informatics, 47, 101245. DOI:10.1016/j.aei.2020.101245

Zhang, J., 2010. Multi-source remote sensing data fusion: status and trends, International Journal of Image and Data Fusion, 1:1, 5-24, DOI: $\underline{10.1080 / 19479830903561035}$

Zhao L, Liu Z, Mbachu J., 2019. An Integrated BIM-GIS Method for Planning of Water Distribution System. ISPRS International Journal of Geo-Information. 8(8):331. DOI:10.3390/ijgi8080331 
Zhu, Z., Donia, S., 2013. Spatial and visual data fusion for capturing, retrieval, and modeling of as-built building geometry and features. Vis. in Eng. 1(10).

DOI:10.1186/2213-7459-1-10. 


\section{Annex 1 Detailed definition of data parameters and integrability assessment.}

Table A1. Pre-assessment of integrability based on general data features.

\begin{tabular}{|c|c|c|c|}
\hline & $\begin{array}{l}\text { Destination data (data } \\
\text { requirements) }\end{array}$ & Input data & Assessment \\
\hline $\begin{array}{l}\text { Geographical } \\
\text { extent }\end{array}$ & $\begin{array}{l}\text { <gml:Envelope } \\
\text { srsDimension="3" } \\
\text { srsName="urn:ogc:def:crs:EPSG } \\
:: 7415 "> \\
\text { <gml:lowerCorner>90000.000 } \\
434963.000 \\
0</ \text { gml:lowerCorner> } \\
\text { <gml:upperCorner>94000.000 } \\
437500.000 \\
\text { 100</gml:upperCorner> } \\
\text { </gml:Envelope> }\end{array}$ & $\begin{array}{l}\text { \#6611258= } \\
\text { IFCCARTESIANPOINT((93191 } \\
\text { 049.7637025,436743261.,0.)); } \\
\# 6611260= \\
\text { IFCDIRECTION((0.6814876127 } \\
\text { 01515,0.731829648029095,0.)); } \\
\text { \#6611262= } \\
\text { IFCAXIS2PLACEMENT3D(\#66 } \\
\text { 11258,\#19,\#6611260); } \\
\text { \#6611263= } \\
\text { IFCLOCALPLACEMENT(\$,\#6 } \\
\text { 611262); } \\
\text { \#6611264= } \\
\text { IFCSITE('Ouc_lgsWD3QgU5Tbt } \\
\text { wvEPN',\#41,'Default',\$,",\#66112 } \\
\text { 63,\$,\$,.ELEMENT.,(42,21,30,34 } \\
\text { 4238),(-71,-3,-35,-- } \\
\text { 194702),5600.\$,\$); }\end{array}$ & $\begin{array}{l}\text { They overlap } \\
\text { (case } 3 \text { Figure } 4 \text { ) }\end{array}$ \\
\hline $\begin{array}{l}\text { Temporal } \\
\text { frame }\end{array}$ & 2017 & 2020 & $\begin{array}{l}\text { Input data are } \\
\text { more recent and } \\
\text { can be suitably } \\
\text { used to update the } \\
\text { map, which is the } \\
\text { goal of the } \\
\text { integration. }\end{array}$ \\
\hline Scope & City & Building & $\begin{array}{l}\text { It overlaps (case B } \\
\text { Figure 4) }\end{array}$ \\
\hline $\begin{array}{l}\text { Goal and } \\
\text { intended use }\end{array}$ & Visualization of city objects & Building design & - \\
\hline Lineage & $\begin{array}{l}\text { Automatically generated by } \\
\text { 3Dfier, extruding the building } \\
\text { footprints until their maximum } \\
\text { height. Input data: Dutch } \\
\text { national digital map } \\
\text { Basisregistratie Addressen and } \\
\text { Gebouwen (BAG) }{ }^{23} \text { and } \\
\text { Actueel Hoogtebestand } \\
\text { Nederland (AHN3) })^{24}\end{array}$ & $\begin{array}{l}\text { Parametrically modelled within } \\
\text { BIM software }\end{array}$ & - \\
\hline $\begin{array}{l}\text { Implementati } \\
\text { on } \\
\text { requirements }\end{array}$ & $\begin{array}{l}\text { Will be visualised in CityGML } \\
\text { viewers, such as Azul (Arroyo } \\
\text { Ohori, 2020). }\end{array}$ & $\begin{array}{l}\text { Needed to be managed in BIM } \\
\text { software to support design and } \\
\text { construction. }\end{array}$ & - \\
\hline Author & $\begin{array}{l}\text { 3D geoinformation group - TU } \\
\text { Delft }\end{array}$ & $\begin{array}{l}\text { Provast - Architect: OZ } \\
\text { Architects }\end{array}$ & - \\
\hline
\end{tabular}

\footnotetext{
${ }^{23}$ https://bag.basisregistraties.overheid.nl [Accessed $2^{\text {nd }}$ December 2021]

${ }^{24}$ https://www.pdok.nl/introductie/-/article/actueel-hoogtebestand-nederland-ahn3- [Accessed 2nd
}

December 2021] 
Table A2. Integrability assessment based on the geometric parameters

\begin{tabular}{|l|l|l|l|}
\hline & $\begin{array}{l}\text { Destination data (data } \\
\text { requirements) }\end{array}$ & Input data & $\begin{array}{l}\text { Assess } \\
\text { ment }\end{array}$ \\
\hline Accuracy & $20 \mathrm{~cm}$ & $\begin{array}{l}1 \mathrm{~cm} \text { (design precision is 1 mm, the } \\
\text { value is lowered to take into account } \\
\text { the possible discrepancy between } \\
\text { design and construction) }\end{array}$ & 4 \\
\hline Abstraction & $\begin{array}{l}\text { lod0FootPrint; lod0RoofEdge; } \\
\text { lod1Solid }\end{array}$ & $\begin{array}{l}\text { Very high level of detail, interior, } \\
\text { exterior, small elements and furniture } \\
\text { are represented }\end{array}$ & 2 \\
\hline Paradigm & lod0FootPrint - gml:MultiSurface & Parametrically modelled solids & 3 \\
\hline Topology & $\begin{array}{l}\text { no relevant info to be taken into } \\
\text { account }\end{array}$ & - & - \\
\hline $\begin{array}{l}\text { Georeferenci } \\
\text { ng }\end{array}$ & EPSG:7415 & EPSG:7415 & 4 \\
\hline $\begin{array}{l}\text { Units of } \\
\text { measure }\end{array}$ & $\mathrm{m}$ & mm & 3 \\
\hline
\end{tabular}

Table A3. Integrability assessment based on the semantic parameters

\begin{tabular}{|c|c|c|c|}
\hline & $\begin{array}{l}\text { Destination data (data } \\
\text { requirements) }\end{array}$ & Input data & $\begin{array}{c}\text { Assess } \\
\text { ment }\end{array}$ \\
\hline \multicolumn{4}{|l|}{ Entities } \\
\hline Terms & $\begin{array}{l}\text { WaterBody, Building, LandUse, } \\
\text { PlantCover, Road - as defined by } \\
\text { CityGML v. } 2\end{array}$ & $\begin{array}{l}\text { Many entities related to building and } \\
\text { building elements (ifcPlate, ifcSlab, } \\
\text { ifcWall, ifcStair, ifcWindow etc.) as } \\
\text { defined by IFC v. } 2 \times 3 \text {. "Building" is the } \\
\text { term used for the entire building. }\end{array}$ & 4 \\
\hline $\begin{array}{l}\text { Vaguenes } \\
\text { s }\end{array}$ & Definitions from CityGML v.2 & $\begin{array}{l}\text { Definitions from IFC documentation. } \\
\text { The part of the model used is in this } \\
\text { case the group of objects } \\
\text { (IfcSpatialStructureElement)"IfcBuildin } \\
\text { g"25 }\end{array}$ & 4 \\
\hline $\begin{array}{l}\text { Approxim } \\
\text { ation }\end{array}$ & Building and city elements & $\begin{array}{l}\text { Building elements, but a class exists for } \\
\text { Building. }\end{array}$ & 4 \\
\hline $\begin{array}{l}\text { Semantic } \\
\text { paradigm }\end{array}$ & $\begin{array}{l}\text { According to the city representation } \\
\text { scope }\end{array}$ & $\begin{array}{l}\text { According to the building design and } \\
\text { construction scope (compatible) }\end{array}$ & 3 \\
\hline Language & English & English & 4 \\
\hline Encoding & $\begin{array}{l}\text { According to CityGML v.2 } \\
\text { (bldg:Building) }\end{array}$ & According to IFC v. $2 \times 3$ (ifcBuilding) & 3 \\
\hline \multicolumn{4}{|l|}{ Attributes } \\
\hline Terms & measuredHeight & Not stored explicitly & - \\
\hline $\begin{array}{l}\text { Vaguenes } \\
\text { s }\end{array}$ & Very clear term & - & - \\
\hline $\begin{array}{l}\text { Approxim } \\
\text { ation }\end{array}$ & $\begin{array}{l}\text { Variations could be in the reference } \\
\text { point measured (top of the roof, gutter } \\
\text { level, intermediate point etc.) }\end{array}$ & - & - \\
\hline $\begin{array}{l}\text { Semantic } \\
\text { paradigm }\end{array}$ & $\begin{array}{l}\text { According to the city representation } \\
\text { scope }\end{array}$ & - & - \\
\hline Language & English & - & - \\
\hline Encoding & $\begin{array}{l}\text { Compliant to CityGML v.2 } \\
\text { "measuredHeight" }\end{array}$ & - & - \\
\hline
\end{tabular}

\footnotetext{
${ }^{25}$ https://standards.buildingsmart.org/IFC/DEV/IFC4_3/RC1/HTML/schema/ifcproductextensio
} n/lexical/ifcbuilding.htm [Accessed 2nd December 2021] 


\begin{tabular}{|c|c|c|c|}
\hline Codelists & Not relevant/present & - & $\begin{array}{l}\text { not } \\
\text { releva } \\
\text { nt }\end{array}$ \\
\hline \multicolumn{4}{|l|}{$\begin{array}{l}\text { Attribute } \\
\text { values }\end{array}$} \\
\hline Terms & - & - & \\
\hline $\begin{array}{l}\text { Vaguenes } \\
\text { S }\end{array}$ & $\begin{array}{l}\text { We cannot know the accuracy of } \\
\text { measurement, but the precision is } 1 \\
\text { centimetre }\end{array}$ & $\begin{array}{l}\text { We can measure maximum height with } \\
\text { centimetre accuracy w.r.t. the designed } \\
\text { building. However, this one should be } \\
\text { measured and checked during the final } \\
\text { construction testing and validation. }\end{array}$ & 1 \\
\hline $\begin{array}{l}\text { Approxim } \\
\text { ation }\end{array}$ & - & - & - \\
\hline $\begin{array}{l}\text { Semantic } \\
\text { paradigm }\end{array}$ & $\begin{array}{l}\text { According to the city representation } \\
\text { scope }\end{array}$ & $\begin{array}{l}\text { According to the building design and } \\
\text { construction scope (it implies that, for } \\
\text { example, we could even store small } \\
\text { details, such as roof furniture and } \\
\text { installations) }\end{array}$ & 3 \\
\hline Language & - & - & - \\
\hline Encoding & $\begin{array}{l}\text { Floating value Expressed in meters } \\
\text { (decimal separator }=\text { point) }\end{array}$ & - & 3 \\
\hline
\end{tabular}

Table A4. Integrability assessment based on the structural parameters

\begin{tabular}{|l|l|l|l|}
\hline & \multicolumn{1}{|c|}{$\begin{array}{c}\text { Destination data (data } \\
\text { requirements) }\end{array}$} & \multicolumn{1}{|c|}{ Input data } & Assessment \\
\hline Is-a hierarchy & Compliant to CityGML v.2 & Compliant to IFC v.2x3 & 3 \\
\hline Granularity & $\begin{array}{l}\text { Smallest object is the } \\
\text { building }\end{array}$ & $\begin{array}{l}\text { Smallest object is the building } \\
\text { element }\end{array}$ & 2 \\
\hline Semantic Paradigm & $\begin{array}{l}\text { According to the city } \\
\text { representation scope }\end{array}$ & $\begin{array}{l}\text { According to the building design } \\
\text { and construction scope }\end{array}$ & 3 \\
\hline Part-of meronimy & Compliant to CityGML v.2 & Compliant to IFC v.2x3 & 3 \\
\hline Granularity & $\begin{array}{l}\text { Smallest object is the } \\
\text { building }\end{array}$ & Smallest object is the space & 2 \\
\hline Semantic Paradigm & $\begin{array}{l}\text { According to the city } \\
\text { representation scope }\end{array}$ & $\begin{array}{l}\text { According to the building design } \\
\text { and construction scope }\end{array}$ & 3 \\
\hline Relationships & No relationships represented & - & - \\
\hline
\end{tabular}

Table A5. Integrability assessment based on the syntactical parameters

\begin{tabular}{|l|l|l|l|}
\hline & \multicolumn{1}{|c|}{$\begin{array}{c}\text { Destination data (data } \\
\text { requirements) }\end{array}$} & \multicolumn{1}{c|}{ Input data } & Assessment \\
\hline Data format & GML3 & STEP Physical File (IFC) & 3 \\
\hline Objects' behaviour & no objects' behaviour present & - & - \\
\hline
\end{tabular}

